IZA DP No. 6305

\title{
Bumpy Rides:
}

School to Work Transitions in South Africa

Todd Pugatch

January 2012 


\title{
Bumpy Rides: School to Work Transitions in South Africa
}

\author{
Todd Pugatch \\ Oregon State University \\ and IZA
}

\section{Discussion Paper No. 6305 \\ January 2012}

IZA

\author{
P.O. Box 7240 \\ 53072 Bonn \\ Germany
}

\author{
Phone: +49-228-3894-0 \\ Fax: +49-228-3894-180 \\ E-mail: iza@iza.org
}

\begin{abstract}
Any opinions expressed here are those of the author(s) and not those of IZA. Research published in this series may include views on policy, but the institute itself takes no institutional policy positions.

The Institute for the Study of Labor (IZA) in Bonn is a local and virtual international research center and a place of communication between science, politics and business. IZA is an independent nonprofit organization supported by Deutsche Post Foundation. The center is associated with the University of Bonn and offers a stimulating research environment through its international network, workshops and conferences, data service, project support, research visits and doctoral program. IZA engages in (i) original and internationally competitive research in all fields of labor economics, (ii) development of policy concepts, and (iii) dissemination of research results and concepts to the interested public.
\end{abstract}

IZA Discussion Papers often represent preliminary work and are circulated to encourage discussion. Citation of such a paper should account for its provisional character. A revised version may be available directly from the author. 


\section{ABSTRACT}

\section{Bumpy Rides: School to Work Transitions in South Africa*}

Re-enrollment in school following a period of dropout is a common feature of the South African school to work transition that has been largely ignored in both the literature on South Africa and the wider literature on sequential schooling choice. In this paper, I quantify the importance of the option to re-enroll in the school to work transition of South African youth. I estimate a structural model of schooling choice in South Africa using a panel dataset that contains the entire schooling and labor market histories of sampled youth. Estimates of the model's structural parameters confirm the hypothesis that enrollment choices reflect dynamic updating of the relative returns to schooling versus labor market participation. In a policy simulation under which re-enrollment prior to high school completion is completely restricted, the proportion completing at least 12 years of schooling rises 6 percentage points, as youth who would have dropped out under unrestricted re-enrollment reconsider the long-term consequences of doing so. The results suggest that the option to re-enroll is an important component of the incentives South African youth face when making schooling decisions.

JEL Classification: $\quad$ I21, J24, O12

Keywords: human capital investment, labor supply, youth unemployment, dynamic discrete choice, South Africa

Corresponding author:

Todd Pugatch

Oregon State University

Department of Economics

325C Ballard Extension Hall

Corvallis, OR 97330

USA

E-mail: todd.pugatch@oregonstate.edu

\footnotetext{
I thank Cally Ardington, Elodie Djemai, Rob Garlick, Jessica Goldberg, Osborne Jackson, Erik Johnson, Laura Kawano, David Lam, Murray Leibbrandt, James Levinsohn, Brian McCall, Zoë McLaren, Peter Orazem, Francesc Ortega, Christina Plerhoples, Kevin Stange, Elias Walsh, Martin Wittenberg, Dean Yang and seminar participants at the University of Cape Town, Oregon State University, the University of Michigan, and several other institutions and conferences for helpful commnets. Cally Ardington, Nicola Branson, Jessica Goldberg, and David Lam oriented me to CAPS and graciously shared their programs for formatting the data.
} 


\section{Introduction}

More than a decade after the fall of apartheid in South Africa, economic outcomes for previously disenfranchised groups remain bleak, particularly for youth: 52\% of 20-24 year olds were unemployed in 2005 (Banerjee, Galiani, Levinsohn, McLaren and Woolard 2008). South Africa's youth unemployment is severe even by the standards of its region, with its employment/population ratio of $14 \%$ far below the Sub-Saharan Africa average of 49\% 11 Behind South Africa's poor youth labor market outcomes lies an especially slow and bumpy transition from school to work: $22 \%$ of 20 yearolds were enrolled in grades K-10 in 2001, reflecting frequent grade repetition and re-enrollment; Figure 1 shows that only Brazil has a higher rate among a group of comparison countries. Numerous studies have examined the mechanisms generating youth economic outcomes in South Africa, but most rely on static theories that assume students have perfect foresight about future job opportunities when making schooling decisions. Even the small number of dynamic sequential schooling models in the wider literature dismiss re-enrollment in school after spells of withdrawal as a "rare event" (Keane and Wolpin 1997, pp. 487) or ignore it entirely. Yet in South Africa, where lack of labor market opportunities and high rates of school failure make enrollment decisions difficult for many youth, re-enrollment is a key feature of the school to work transition: in my sample, almost one third re-enroll at some point in their schooling careers, including $21 \%$ before completing high school $2^{2}$ While static models are incapable of explaining this irregular enrollment behavior, re-enrollment becomes sensible in a dynamic context in which youth are uncertain about future outcomes and the returns associated with their choices.

This paper aims to fill this gap in the literature by quantifying the importance of the option to reenroll in the South African school to work transition. Specifically, I develop and estimate a dynamic model of school advancement and job search that allows for uncertain outcomes and re-enrollment following dropout during the schooling career. As youth learn the results of their enrollment and job search choices, they update their expectations about the relative returns to enrollment versus labor market participation, leading some who dropped out of school to re-enroll. In addition to explaining observed patterns of school enrollment, completion, and labor market participation, I quantify the importance of re-enrollment by conducting simulations in which the option to reenroll before completing high school is restricted. I find that the re-enrollment restriction increases the proportion completing at least 12 years of schooling by 6 percentage points, as youth who would have dropped out under unrestricted re-enrollment reconsider the long-term consequences of doing so. To my knowledge, this is the first dynamic, sequential schooling model applied to South

\footnotetext{
${ }^{1}$ Data refers to 15-24 year olds for 2005, from World Bank Africa Development Indicators.

${ }^{2}$ Comparable rates in the NLSY79 for the United States are 20\% and 5\%, respectively (Keane and Wolpin 1997).
} 
African data, and the first in the wider development literature to focus on the importance of school re-enrollment after periods of dropout.

The difficult school to work transition of South African youth in the post-apartheid era has been well documented. Racial disparities in school quality and student outcomes found under apartheid (Case and Deaton 1999, Case and Yogo 1999) persisted in the post-apartheid era (Yamauchi 2005). In the post-apartheid school system, high rates of grade repetition lead to lengthy school careers for black and coloured youth (Fiske and Ladd 2004, Lam, Ardington and Leibbrandt 2011), while transitions from school to employment are slow, with only $37 \%$ of black males aged 21-22 reporting ever obtaining employment (Lam, Leibbrandt and Mlatsheni 2009). When facing such poor labor market outcomes, forward-looking agents may find it optimal to remain in school despite relatively low probabilities of advancement. Others may drop out and later re-enroll if unsuccessful in the labor market. Static human capital investment models, however, will not capture this behavior if agents adapt their expectations and alter their choices due to acquisition of new information, making a dynamic model appropriate. Eckstein and Wolpin (1999), Arcidiacono (2004), Stange (2009) and Joensen (2008), among others, estimate dynamic schooling models in which agents face uncertainty over academic advancement and labor market opportunities.

Like each of those studies that use dynamic schooling models, the model in this paper will allow agents to update their expectations about the relative returns to school enrollment and labor market participation in a dynamic discrete choice framework. I extend the previous work by allowing for an option to re-enroll in school after a spell of labor market participation, an important feature of school to work transitions in South Africa that prevailing dynamic schooling models have overlooked ${ }^{3}$ The pervasiveness of adverse shocks to South African youth - grade repetition while in school, high and lengthy unemployment when in the labor market - lead to the frequently rocky transitions from school to work observed in the data. Dropouts who update their expectations about future labor market opportunities during labor market spells may choose to re-enroll as a result. In this paper, I model these transitions and estimate their underlying structural parameters.

Estimates of the model's structural parameters confirm the hypothesis that enrollment choices reflect dynamic updating of the relative returns to schooling versus labor market participation. The model replicates basic patterns of enrollment, grade advancement and employment observed in the data, according to characteristics such as completed schooling and recent and cumulative school failures. I use my estimates of the underlying structural parameters relevant to enrollment

\footnotetext{
${ }^{3}$ There are important exceptions. Keane and Wolpin (1997) do not restrict re-enrollment in their model despite referring to it as a "rare event" (pp. 16), while Eckstein and Wolpin (1999) allow re-enrollment within 5 years of entering high school. Belzil and Hansen (2002) estimate a dynamic discrete choice model of school enrollment that allows for re-enrollment after periods of "interruption," but they assume that such interruptions occur exogenously. Light (1995) estimates a hazard model of re-enrollment. Each of these studies uses U.S. data.
} 
to conduct policy simulations. To quantify the importance of re-enrollment, I simulate the model under removal of the re-enrollment option. Enrollment rates rise sharply throughout the schooling distribution after restricting re-enrollment before high school completion, relative to both the data and results from the unrestricted model. I find that the re-enrollment restriction increases the proportion completing at least 12 years of schooling by 6 percentage points: by increasing the opportunity cost of dropout, restricted re-enrollment prolongs enrollment spells. Absent sources of market failure, however, such a policy would reduce social welfare, and is therefore intended as a useful thought experiment about the incentives to re-enroll rather than a specific policy proposal. Additional policy simulations, such as enforcement and extension of compulsory schooling, lead to qualitatively similar results as the restricted re-enrollment simulation. The results suggest that the option to re-enroll is an important component of the incentives South African youth face when making schooling decisions.

I organize the paper as follows. Section 2 develops the formal model and explains the estimation method. Section 3 describes the data. Section 4 presents results, model fit, and robustness checks. Section 5 presents results of policy simulations. Section 6 concludes.

\section{A model of the school to work transition}

\subsection{Weaknesses in existing static and dynamic human capital models}

Standard, static human capital investment models, such as the canonical Becker (1994) model, have difficulty explaining re-enrollment. Such models assume that the agent faces no uncertainty over schooling outcomes or the shapes of the earnings and cost functions, and therefore need not update her choice of schooling as new information about its returns (due to say, imperfect knowledge of ability or labor market opportunities) arrives. Yet such dynamic considerations are likely to be quite important to schooling choices, particularly for young adults. As Card (1999, pp. 18101812) acknowledges, "In fact the transition from school to work is often a bumpy one, as young adults move back and forth between full-time or part-time enrollment and part-time or full-time work...individuals do not necessarily know the parameters of their earnings functions when they make their schooling choices."

To address these concerns, a number of studies develop and estimate dynamic human capital models, in which agents may update their schooling decisions based on the arrival of new information about academic ability (Eckstein and Wolpin 1999, Stange 2009) and labor market opportunities (Keane and Wolpin 1997, Joensen 2008). However, even in most dynamic models (such as Heckman and Navarro 2007, Joensen 2008, Stange 2009), exiting school to enter the la- 
bor market is a terminal action. While this assumption may be appropriate for settings where re-enrollment in school after a spell in the labor market is rare, South African youth face high levels of grade repetition and unemployment that magnify the uncertainty associated with their enrollment choices and make them especially vulnerable to adverse shocks as they transition from school to work. The corresponding prevalence of re-enrollment in South Africa make re-enrollment essential to incorporate in a dynamic human capital model.

Under what circumstances will an agent with the option to re-enroll choose to do so? If agents choose schooling sequentially based on all available information at the time of their choice, they might re-enroll after updating their expectations about the relative returns to enrollment versus labor market participation $4^{4}$ For instance, a dropout who fails to find a job may update her expectations about future employment and decide that re-enrollment in school is a better option than continued job search. Such behavior is a rational response to the acquisition of new information based on the outcomes of past choices, but the dynamic updating that drives re-enrollment in this scenario is absent from static human capital models 5

\section{$2.2 \quad$ Timing and preferences}

Building on the intuition for re-enrollment described in the previous section, I develop a model of enrollment choice in the presence of uncertain schooling and labor market outcomes. I then explain how I estimate the structural parameters of the model using panel data on South African youth.

Consider an agent who makes discrete choices about school enrollment and labor market participation to maximize utility over a finite lifetime. In each period, the agent observes the state vector $S_{t}$, which summarizes all information relevant to her choice at time $t$. She then chooses whether to enroll in school or enter the labor market; let $d_{t}=\mathbb{I}$ (enroll at time $\left.t\right)$. Simultaneous enrollment and labor market participation is absent from the model because it rarely occurs among South African youth, a point I return to in Section 3.1. The agent may enroll in periods $t=t_{0}, \ldots, T_{d}$, but in all subsequent periods $t=T_{d}+1, \ldots, T$, the agent participates in the labor market. In each period, the agent receives choice-specific flow payoffs $U_{t}^{d}\left(S_{t}\right)$. Thus the agent's optimization problem at any time in the decision period $t \leq T_{d}$ is:

$$
\max _{d} \mathbb{E}\left[\sum_{t=\tau}^{T_{d}} \beta^{t-\tau}\left\{d_{t} U_{t}^{e}\left(S_{t}\right)+\left(1-d_{t}\right) U_{t}^{j}\left(S_{t}\right)\right\}+\sum_{t=T_{d}+1}^{T} \beta^{t-\tau} U_{t}^{j}\left(S_{t}\right)\right]
$$

\footnotetext{
${ }^{4}$ The notion that dynamic updating could drive re-enrollment accords with Heckman and Navarro (2007). Their sequential schooling model does not allow re-enrollment, but they nonetheless speculate, "In a general model, different persons could drop out and return to school at different times as information sets are revised" (pp. 364).

${ }^{5}$ In an unpublished appendix available upon request, I formalize this argument with a stylized model in which $e x$ ante identical agents make different re-enrollment choices based on the outcomes of their initial job search.
} 
where $U^{e}$ and $U^{j}$ are the utility functions for enrollment and labor market participation, respectively; $\beta$ is the agent's discount factor; and the expectation is taken with respect to the evolution of the state space. The indirect utility functions are expressed in monetary units (South African rand per year), and capture the agent's preferences for enrollment and labor market participation as a function of $S_{t}$. I assume the agent is risk neutral. I also assume that the utility functions are additively separable in observable (to the econometrician) components $X_{t}$ and choice-specific shocks observed only by the agent, $\epsilon_{t}^{d}$, so that $U_{t}^{d}\left(S_{t}\right)=u_{t}^{d}\left(X_{t}\right)+\epsilon_{t}^{d}$. The agent learns the shocks $\epsilon_{t}=\left(\epsilon_{t}^{j}, \epsilon_{t}^{e}\right)$ at the beginning of each period, prior to the enrollment decision.

If the agent chooses to enter the labor market, she must search for employment, with probability of success conditional on current information contained in $S$. Her flow payoff in the labor market is her expected wage, i.e., the product of the probability that she will find employment and the wage she would earn if successful, all conditional on information known at the beginning of the period ${ }^{6}$

$$
\begin{aligned}
U_{t}^{j}\left(S_{t}\right) & =\mathbb{E}\left[w\left(X_{t}\right)\right]+\epsilon_{t}^{j} \\
& =\operatorname{Pr}\left(\operatorname{work} \mid X_{t}\right) \times w\left(X_{t}\right)+\epsilon_{t}^{j}
\end{aligned}
$$

I model wages as a linear function of the observable state variables, i.e., $w\left(X_{t}\right)=X_{t} \gamma$. The probability of working is estimated as a logit that is linear in the same covariates as the wage equation $\sqrt{7}$

If the agent chooses to enroll in school, she passes the grade level and accumulates associated human capital with probability that depends on the current state. Her payoffs depend on her net psychic benefits of schooling (b) based on all information known at period $t$, less the school fee. Thus we have:

$$
U_{t}^{e}\left(S_{t}\right)=b\left(X_{t}\right)-f e e\left(X_{t}\right)+\epsilon_{t}^{e}
$$

The net psychic benefits of schooling include the agent's self-assessment of her ability based on both pre-determined characteristics and her schooling outcomes up to year $t$, as well as other

\footnotetext{
${ }^{6}$ Note that I implicitly normalize the value of unemployment to zero, consistent with the absence of a widely accessible unemployment insurance system in South Africa.

${ }^{7}$ This treatment of job search nests the approach of a companion paper that analyzes youth's first post-school labor market experiences using the same dataset (Levinsohn and Pugatch 2011). That paper estimates $\operatorname{Pr}\left(\right.$ work $\left.\mid X_{t}\right)=$ $q\left(X_{t}\right) \times\left(1-F_{w \mid X}\left(w^{*}\right)\right)$, where $q$ is the arrival rate of job offers, $F$ is the wage offer distribution, and $w^{*}$ is the reservation wage. Whereas that paper focused on disentangling $q$ from the parameters of $F$ under alternative measures of the reservation wage, my focus here is on the relative returns to enrollment versus job search, for which the distinction between the arrival rate and distribution of wage offers is less important. Therefore, I choose to forego estimation of these parameters, which simplifies estimation of the model.
} 
characteristics that may influence the non-monetary benefits and costs of school. I parameterize $b$ as a linear function of $X$, i.e., $b\left(X_{t}\right)=X_{t} \alpha$. School fees also depend on individual characteristics $X$, which allows fees to vary by race and school level, consistent with South Africa's educational institutions.

Table 1 describes the elements of $X$, with further details in Section 3 and Appendix $B$. The table also notes the exclusion restrictions for the utility functions (2) and (3) and the transition equations for enrollment and passing (described in the next subsection) ${ }^{8}$ The state space $X$ includes race and gender dummies; indicators for ability quartiles based on results from a standardized test administered in Wave 1 of the panel; a dummy for completion of grade 6 or higher at age 12 9 when the model begins; a dummy for enrollment in the previous period, to capture switching costs between enrollment and labor force participation; and a dummy for co-residence with a pensioneligible grandparent, consistent with evidence that public pension receipt may fund the schooling or job search of youth in the household (Duflo 2003, Case 2004, Edmonds 2006, Souza 2010) ${ }^{10}$ The model assumes that the returns to schooling are linear, but allows for changes in slope and intercept at high school completion 11 By including time-varying covariates such as work experience and an indicator for employment in the last relevant period, the model allows agents to update their expectations of labor market outcomes based on the results of past choices (pass or fail for enrollment, work or search for job search) 12

In the enrollment utility function, I account for (possible) credit constraints by including indicators for lower quintiles of household incomes ( $y_{q}$ for quintiles $q=1,2$ ) and their interaction with a dummy for high school graduate $(H S G)$, reflecting the potential difficulties youth from lowerincome households face in financing post-secondary education 13 The completed schooling terms

\footnotetext{
${ }^{8}$ These exclusion restrictions are theoretically motivated, and not necessary for identification.

${ }^{9}$ Completing grade 6 by age 12 represents "on-time" school completion for students who enter at age 6 , the modal school entry age in South Africa.

${ }^{10}$ Note, however, that I assume that pension receipt is unexpected. This avoids the multiplication of the state space required to allow the ages and mortality risk of co-resident grandparents to evolve. Edmonds (2006) finds that the labor supply responses of youth to household pension receipt are as though pension income is unanticipated.

${ }^{11}$ Case and Yogo (1999) also find evidence for a slope change in the returns to schooling at high school completion, although their outcome measure is log wages, whereas my outcome is expected wages.

${ }^{12}$ In addition to the state variables in Table 1. I also assume that expected wages evolve with a quadratic trend in age beginning at the close of the decision horizon $\left(t=T_{d}+1\right)$ until the end of the model at $t=T$. I restrict the age-expected wage profile to begin at $t=T_{d}+1$ for several reasons. First, because no individual in the data is observed after age $26\left(t=T_{d}+3\right)$, I prefer to control for actual work experience, rather than age, prior to $T_{d}$. Second, estimating age coefficients with wage data on such young agents is likely to be biased, so I use auxiliary data from the 2001 South African Census to estimate the age-expected wage profile. Details may be found in Appendix B

${ }^{13}$ This method of allowing household income to proxy for credit constraints follows Cameron and Heckman (2001), Carneiro and Heckman (2002) and Lam, Ardington, Branson, Goostrey and Leibbrandt (2010), although the resulting estimates may reflect the accumulation of educational disadvantage in low income households, rather than credit constraints. Formally incorporating credit constraints would require a richer model that incorporates asset accumulation and savings, as in Keane and Wolpin (2001) and Cameron and Taber (2004).
} 
$\left(s, H S G, s_{p s}\right)$ capture how the net psychic benefit of schooling evolves over time. The failure terms $\left(f, f_{\text {tot }}\right)$ capture how the agent dynamically updates her self-assessed academic ability; including separate terms for recent and cumulative school failure allows the agent to place different weight on recent versus past outcomes 14 Figure 2 summarizes timing, choices, and payoffs in the model.

\subsection{State transitions}

Because the choice environment is dynamic, the agent considers not only current payoffs when deciding to enroll in school, but also how the current period's choice affects expected future payoffs. Following standard practice in dynamic discrete choice models, I assume that transitions of the state variable follow a first-order Markov process, and that transitions of the unobserved shocks are conditionally independent from those of the observed state 15

In the present model, an agent choosing to enter the labor market considers the probability of finding employment in the current period, which enters the labor market utility function, as well as the effect that current success or failure in job search will have on future job opportunities, which enters the state transition function. Because work experience variables are the only elements of the state space that evolve during periods in which the agent enters the labor market, the corresponding state transition simplifies to the probability that the agent finds work:

$$
\begin{aligned}
\operatorname{Pr}\left(X_{t+1} \mid X_{t}, d_{t}=0\right) & =\operatorname{Pr}\left(x_{t+1}=1, x_{t o t, t+1}=x_{t o t, t}+1 \mid X_{t}, d_{t}=0\right) \\
& =\operatorname{Pr}\left(\operatorname{work} \mid X_{t}, d_{t}=0\right)
\end{aligned}
$$

\footnotetext{
${ }^{14}$ The process of dynamic updating of the net psychic benefits of schooling in the model may be viewed as an approximation to Bayesian updating. Partition $X_{t}$ into $\left[\mathcal{X}_{0}, \mathcal{X}_{t}\right]$, representing its time-invariant and time-varying elements, respectively. If both the prior and posterior distributions for $b$ are normal, then the posterior mean $\mathbb{E}\left[b \mid X_{t}\right]$ is a linear combination of the prior mean $\mathbb{E}\left[b \mid \mathcal{X}_{0}\right]$ and the mean of $\mathcal{X}_{t}$ :

$$
\mathbb{E}\left[b \mid X_{t}\right]=a_{1} \mathbb{E}\left[b \mid \mathcal{X}_{0}\right]+a_{2} \overline{\mathcal{X}}_{t}
$$

where $a_{1}=\frac{1 / \sigma_{b}^{2}}{\left(1 / \sigma_{b}^{2}\right)+t \sigma_{X}^{2}}$ and $a_{2}=\frac{t \sigma_{b}^{2}}{\left(1 / \sigma_{b}^{2}\right)+t \sigma_{X}^{2}}$. Here, $\sigma_{b}^{2}$ and $\sigma_{X}^{2}$ are the variances of $b$ and $\mathcal{X}_{t}$, respectively. Note that as $t$ increases, the agent places relatively more weight on $\mathcal{X}_{t}$ when updating $\mathbb{E}\left[b \mid X_{t}\right]$, reflecting the importance of new information. Stange (2009) gives a similar interpretation of the agent's updating rule, noting that the process is similar to the normal learning model.

${ }^{15}$ These assumptions allow me to estimate transitions of next period's observed state $X_{t+1}$ as a function of the current observed state $X_{t}$ only. This simplification comes at a cost, as it assumes that the transition probability for $X_{t+1}$ depends on unobserved shocks only through their influence on the current state variable. This property would not hold if, for instance, an unobserved negative household shock that does not cause a youth to fail the current grade nonetheless persists and affects the following period's academic performance, leading her to fail the subsequent grade. However, assuming that persistent shocks affect the observed state variable upon impact, thereby allowing the current observed state to serve as a sufficient statistic for the distribution of next period's observed state, seems reasonable given the large gain in computational tractability.
} 
Similarly, for periods in which the agent enrolls in school, the state transition simplifies to the probability that the agent will pass the grade level 16

$$
\begin{aligned}
\operatorname{Pr}\left(X_{t+1} \mid X_{t}, d_{t}=1\right) & =\operatorname{Pr}\left(s_{t+1}=s_{t}+1, f_{t+1}=0, f_{\text {tot }, t+1}=f_{\text {tot }, t} \mid X_{t}, d_{t}=1\right) \\
& =\operatorname{Pr}\left(\operatorname{pass} \mid X_{t}, d_{t}=1\right)
\end{aligned}
$$

I estimate both state transitions (4) and (5) as logits that are linear in $X_{t}$, using data on labor market and schooling outcomes, respectively 17 The labor market utility function (2) and employment probability (4) functions also include the macro environment indicator $\zeta$, but for simplicity agents forecast next period's macro state to be identical to the present. Denote the logit parameters governing the labor market transition (4) and enrollment transition (5) as $\phi_{j}$ and $\phi_{e}$, respectively.

\subsection{Model Solution and Estimation}

Because the model has a finite horizon, it may be solved by backward recursion. Via Bellman's principle of optimality, rewrite the agent's problem as a dynamic programming problem, where the value function $V_{t}$ is defined as the maximal expected present value of utility at time $t$, conditional on the state $S_{t}$ :

$$
V_{t}\left(S_{t}\right)=U_{t}\left(S_{t}\right)+\beta \mathbb{E}\left[V_{t+1}\left(S_{t+1}\right)\right]
$$

Because the value function assumes optimizing behavior by the agent from period $t$ forward, it may also be expressed as the maximum over alternative-specific value functions:

$$
\begin{aligned}
V_{t}\left(S_{t}\right) & =\max _{d}\left\{V_{t}^{d}\right\} \\
& =\max _{d_{t}}\left\{U_{t}^{d}\left(S_{t}\right)+\beta \mathbb{E}\left[\max _{d_{t+1}}\left\{V_{t+1}^{d}\left(S_{t+1}\right)\right\} \mid S_{t}, d_{t}\right]\right\}
\end{aligned}
$$

The assumptions of additive separability and conditional independence of the state space allow

\footnotetext{
${ }^{16}$ This treatment of the state transition while enrolled follows Lam et al. (2011), who model school progression as the outcome of a threshold advancement rule with stochastic shocks.

${ }^{17}$ The state transitions may also be estimated nonparametrically. Since $X$ is discrete, a simple bin estimator would make nonparametric estimation particularly straightforward, for example. However, because many covariate cells would have few observations, consistent estimation of the state transitions using nonparametric methods would be difficult, so I opt instead for parametric estimation using logits.
} 
me to treat the $\mathbb{E}[\max ]$ term in (7) as a double integral over the marginal distributions of $X$ and $\epsilon$. I discussed the transitions of $X$ in the previous section. To make the problem tractable for estimation, I must assume a parametric form for the distribution of $\epsilon$. I assume that the unobserved shocks are independently and identically distributed Type I extreme value (EV), i.e., $F\left(\epsilon_{t}^{d}\right)=$ $\exp \left(-\exp \left(-\epsilon_{t}^{d}\right)\right)$. The i.i.d. assumption on $\epsilon$ implies that unobserved shocks affecting enrollment utility occur independently from those affecting labor market utility. Although it is easy to think of unmodeled shocks that could affect enrollment and labor force participation simultaneously (illness, household job loss, etc.), many types of shocks, such as the transfer of a talented teacher or the unexpected destruction of a job due to demand-side factors, will affect the utility of just one choice. Assuming that $\epsilon$ is drawn from an i.i.d. Type I EV distribution allows me to write $\mathbb{E}[\max ]$ in closed form, a considerable computational savings.

The assumptions of additively separable utility and conditionally independent and i.i.d. Type I EV shocks allow me to rewrite the $\mathbb{E}[\max ]$ terms of the Bellman equation as:

$$
\begin{aligned}
\mathbb{E}\left[V_{t+1}\left(S_{t+1}\right) \mid S_{t}, d_{t}\right] & =\mathbb{E}\left[\max _{d}\left\{V_{t+1}^{d}\left(S_{t+1}\right)\right\} \mid S_{t}, d_{t}\right] \\
& =\mathbb{E}\left[\ln \left(\sum_{d} \exp \left[V_{t+1}^{d}\left(X_{t+1}\right)\right]\right) \mid X_{t}, d_{t}\right]+\nu
\end{aligned}
$$

where $\nu \cong .577$ is Euler's constant. Substituting the above expression into $(7)$ serves to calculate the agent's expectations over the unobserved state variables $\epsilon$. Combined with my assumptions on the transitions of the discretized observable state variables $X$, we have:

$$
\mathbb{E}\left[V_{t+1}\left(S_{t+1}\right) \mid S_{t}, d_{t}\right]=\sum_{X}\left(\left[\ln \left(\sum_{d} \exp \left[V_{t+1}^{d}\left(X_{t+1}\right)\right]\right) \mid X_{t}, d_{t}\right]+\nu\right) \operatorname{Pr}\left(X_{t+1} \mid X_{t}\right)
$$

The model's structural parameters are $\theta=\left(\phi_{j}, \phi_{e}, \gamma, \alpha\right)$, where $\phi_{j}$ and $\phi_{e}$ are the labor market and enrollment transition parameters; $\gamma$ is the parameter vector for the wage equation; and $\alpha$ is the parameter vector describing enrollment preferences. For any value of $\theta$, we may solve the model recursively by using the terminal condition that following the close of the decision horizon at $T_{d}$, the agent must enter the labor market. Therefore, I set $U_{t}^{e}\left(X_{t}\right)=U_{t}^{j}\left(X_{t}\right)=\mathbb{E}\left(w \mid X_{t}\right)+\epsilon_{t}^{j}$ for all $t>T_{d}$, which allows me to solve for the value functions in periods $t=T_{d}+1, \ldots, T$ by backward induction. The Type I EV assumption on the distribution of utility shocks and their conditional independence over choice alternatives allow me to express the agent's conditional enrollment probability as: 


$$
\operatorname{Pr}\left(d_{t}=1 \mid X_{t}\right)=\frac{\exp \left(V_{t}^{e}\left(X_{t}\right)\right)}{\exp \left(V_{t}^{e}\left(X_{t}\right)\right)+\exp \left(V_{t}^{j}\left(X_{t}\right)\right)}
$$

With data on the sequence of enrollment choices $\left\{d_{t}\right\}_{t=1}^{T_{d}}$, I decompose an individual's contribution to the likelihood function as:

$$
\begin{aligned}
& l_{e}\left(\phi_{e}\right)=\prod_{t=1}^{T_{d}} \operatorname{Pr}\left(\operatorname{pass}_{t} \mid X_{t}, d_{t}=1\right)^{d_{t}} \\
& l_{j}\left(\phi_{j}\right)=\prod_{t=1}^{T_{d}} \operatorname{Pr}\left(\operatorname{work}_{t} \mid X_{t}, d_{t}=0\right)^{1-d_{t}} \\
& l_{w}(\gamma)=\prod_{t=1}^{T_{d}} f\left(w\left(X_{t}\right)^{\mathbb{I}\left(\text { work }_{t}\right)}\right) \\
& l_{d}(\alpha)=\prod_{t=1}^{T_{d}} \operatorname{Pr}\left(d_{t}=1 \mid X_{t}\right)^{d_{t}} \operatorname{Pr}\left(d_{t}=0 \mid X_{t}\right)^{1-d_{t}}
\end{aligned}
$$

where the components are the grade transition (11), the labor market transition (12), the wage equation $(13)^{18}$ and the enrollment choice equation $(14)$. The individual's likelihood contribution is then:

$$
l(\theta \mid X)=\prod_{t=1}^{T_{d}} l_{e} \cdot l_{j} \cdot l_{w} \cdot l_{d}
$$

With panel data $\left\{d_{i t}, X_{i t}\right\}_{t=1}^{T_{d}}$ for $i=1, \ldots, n$ individuals, the likelihood function becomes:

$$
L(\theta \mid X)=\sum_{i=1}^{n} \ln l_{i}\left(\theta \mid X_{i}\right)
$$

Estimation of $\theta$ may proceed by a nested fixed point (NFXP) algorithm, as in Rust (1987): in the "inner loop," the current guess of $\theta$ is used to solve the model recursively, as described above, while in the "outer loop," each guess of $\theta$ is updated through a numerical optimization procedure. The process repeats until convergence.

Because the likelihood function is additively separable in the contributions of enrollment $(d=1)$ and labor market $(d=0)$ components, I am able to estimate these parts sequentially. First, I use

\footnotetext{
${ }^{18}$ Here, $f(\cdot)$ is the density of the wage residuals. In practice, I estimate 13 by linear regression rather than maximum likelihood.
} 
data on employment and school advancement to estimate $\left(\phi_{e}, \phi_{j}\right)$ using (11) and (12); accepted wage data are used to estimate $\gamma$ using (13). The resulting estimates are then substituted into (14) to estimate $\alpha$. To obtain final parameter values and consistent estimates of their standard errors, I conduct one Newton iteration over the full information likelihood function, using the sequential estimates as starting values (McFadden 1984, p. 1426) 19 I set the discount factor $\beta$ to 0.95 . The likelihood function converges to identical parameter estimates from several different arbitrary starting values.

\subsection{Parameter Identification}

This subsection discusses identification of the model's structural parameters $\theta=\left(\phi_{j}, \phi_{e}, \gamma, \alpha\right)$. Employment and grade advancement probabilities conditional on observable characteristics identify the transition parameters $\phi_{j}$ and $\phi_{e}$, respectively, as in standard logistic regressions for binary outcomes. Variation in state variables across individuals and over time among those in the labor market identifies $\gamma$, the parameters of the wage function. Although $\gamma$ is identified from the selected sample that chooses to participate in the labor market and therefore may not be interpreted as causal, the discrete choice model fully specifies the selection process. Differences in enrollment rates by net psychic benefits of schooling $(b)$, both across individuals and over time, identifies the enrollment utility function parameters $\alpha$. For example, the difference in enrollment rates between those who failed their last grade enrolled and those who passed identifies the coefficient on the failure indicator in (3).

The transition parameters $\phi_{e}$ and $\phi_{j}$ capture youth expectations about future schooling and labor market outcomes, respectively. The parameters $\alpha$ and $\gamma$ capture expectations about the utility associated with enrollment and labor force participation, respectively. Precise estimation and sensible signs of coefficients on time-varying characteristics within each structural parameter would provide evidence in favor of my hypothesis that youth dynamically update their expectations about the relative returns to enrollment versus labor market participation. The most notable coefficients are those on school failure and work experience (recent and cumulative), as such coefficients reflect updating based on previously uncertain schooling and labor market outcomes. Evidence of dynamic updating may also be found in the schooling coefficients (schooling, the indicator for high school graduate, and their interaction), because completed schooling also evolves based on past enrollment choices and their outcomes.

\footnotetext{
${ }^{19}$ The exception is the wage equation parameter $(\gamma)$, which is not identified separately from the enrollment preference parameter $(\alpha)$ because only differences in utility matter in binary choice estimation. I report values of $\gamma$ obtained from sequential estimation in the results.
} 


\section{Data}

\subsection{The Cape Area Panel Study}

I use data from the Cape Area Panel Study (CAPS), a longitudinal study of youth in metropolitan Cape Town, South Africa (Lam, Ardington, Branson, Case, Leibbrandt, Menendez, Seekings and Sparks 2008) 20 CAPS sampled about 4,800 youth aged 14-22 in Wave 1 (2002) and currently includes four publicly available waves, the most recent conducted in 2006. In Wave 1, retrospective life histories were collected for each year stretching back to birth, and include information on school enrollment and advancement, job search, and employment. I update this retrospective life history data with information from Waves 2-4 to construct the panel used in this paper. I make several sample restrictions. I drop white youth, as they tend to enjoy living standards comparable to those in developed countries, and my focus here is on youth who tend to face high uncertainty in their schooling and employment outcomes ${ }^{21}$ I keep only those youth observed until at least age 18. I also drop those with inconsistent schooling histories (details described in Appendix B), leaving $N=3,374$ individuals in the sample, comprising 61,314 person-years from ages 4-26. Table A1 shows the panel balance at selected ages. The sample size drops sharply at later ages due to both the young ages of entry into the panel (i.e., right-censoring) and attrition in later waves, but there is no evidence of differential attrition by race.

At each age, the data contain information on the youth's enrollment status. If enrolled, the data report the school outcome (pass or fail) 22 if in the labor market, the data report whether employed ${ }^{23}$ Enrollment in school supersedes labor market participation when these are reported to occur simultaneously at a given age, in order to keep these choices consistent with their treatment as mutually exclusive in the model. Work or search while enrolled peaks at $3 \%$ across all grade levels, and never exceeds $2 \%$ during grades 1-12, making me confident that modeling enrollment as distinct from labor force participation is reasonable. Monthly calendar data collected during CAPS Waves

\footnotetext{
${ }^{20}$ CAPS is publicly available at http://www. caps.uct.ac.za/.

${ }^{21}$ Including whites in the sample leads to qualitatively similar results, however. Results in unpublished appendix, available upon request.

22 "Failure" refers to any type of failure to complete a grade level while enrolled, and includes withdrawal from school as well as academic failure. For post-secondary education (grades 13-16), I expand the definition of grade advancement to include a response of "no grade/continuing" to the survey question on school result, as this is consistent with continuation in a multi-year degree program, and is the modal response for these grades. Unfortunately I am unable to distinguish reliably whether those in post-secondary education are making satisfactory progress to degree completion, because few students report academic failure in these grades.

${ }^{23}$ Although search behavior is also reported in the sample, all non-enrolled youth are assumed to be participating in the labor market. In principle, the model could be extended to include non-participation in the labor market as a discrete choice. However, a companion paper using CAPS (Levinsohn and Pugatch 2011) finds that $64 \%$ of those who permanently exit school and never report searching nonetheless find employment by the end of the sample, suggesting that labor market participation is not synonymous with active search for these youth.
} 
1-4 verify that school enrollment and labor force spells last at least one year on average, regardless of whether I allow a spell to include other concurrent activities or restrict the definition to full-time spells 24 Moreover, school enrollment spells tend to follow the January-December academic year, with $48 \%$ of enrollment spells beginning in January or February and $55 \%$ ending in November or December, making my assumption in the model that time periods last one year seem reasonable. Data on accepted wages and school fees are available only at each panel interview rather than at each age. To overcome this restriction, I predict wages and school fees by regressing observed values on the state variables in Table $1^{25}$ Appendix $\mathrm{A}$ contains additional information on the South African education system, while Appendix B contains additional information on the sample and variable definitions.

For the purposes of the model, the first decision period $t_{0}$ occurs at age 12 , as no youth enter the labor market and obtain work prior to this age, so extending the model to an earlier age would be superfluous. Of course, by age 12 substantial, non-random differences have already arisen among youth due to unobserved characteristics related to family background and motivation. Therefore, I include a dummy for completion of at least 6 years of schooling at age 12 as a state variable (representing "on-time" completion for a student who enters at age 6), which proxies for the effect of such early life differences. The decision period ends at $T_{d}=24$. The model ends at $T=60$, the age of public pension eligibility in South Africa 26

\subsection{Summary statistics and stylized facts}

Table 2 presents summary statistics for the sample. The racial distribution reflects the unique racial composition of Cape Town, where coloureds (mixed racial heritage) are prominent. Schooling careers range on average from ages 6 to 18, with a mean of 1.4 grades failed. There is wide variation (standard deviation 1.3 years) in completed schooling even by age 12 . Only slightly more than half of the sample has worked, though this in part reflects right-censoring of school careers rather than

\footnotetext{
${ }^{24}$ The mean durations of school, work, and labor force participation spells have a minimum of 13.6 months in the monthly calendar data. However, removal of censored spells reduces the minimum mean duration to 7.4 months, because the longest spells tend to be censored.

${ }^{25}$ I predict school fees using only a dummy for black, completed schooling, and a dummy for high school graduate, to be consistent with racial disparities in school expenditure and the discontinuous jump in fees in post-secondary schooling. I am concerned that if additional information on, say, cumulative grades failed were used to predict school fees, results could reflect unmodeled endogenous school choice and therefore be biased. For both expected wages and school fees, I replace predicted values below the minimum value observed in the sample with the first percentile from the data, in order to avoid non-positive predicted values and extreme outliers.

${ }^{26}$ Although individuals must also pass a means test to receive a public pension, in practice about $80 \%$ of elderly blacks and coloureds receive the pension. The pension is quite generous relative to the median incomes of these groups (Case 2004). The pension eligibility age for males was 65 during much of the CAPS Wave 1-4 survey period. I chose $T=60$ for simplicity in estimation, and later check robustness to setting $T=65$.
} 
failure in job search. As mentioned in Section 1, almost one third of the sample has re-enrolled in school (after disenrolling for at least one year) at some point in the sample, including $21 \%$ who re-enroll before completing secondary school. This re-enrollment behavior is difficult to reconcile with standard human capital theory, but is a prominent feature of the dynamic model I estimate ${ }^{27}$

Table 3 depicts patterns of enrollment and school failure by level of completed schooling. Enrollment rates are relatively high among those in the primary and early secondary school grades (1-9), though not universal 28 falling steadily to a trough of $17 \%$ at high school completion. Those with some post-secondary education (grades 13 and above) tend to remain enrolled, however. Enrollment and failure rates are negatively correlated, with failure highest between 9-11 years of completed schooling (when students prepare to pass the "matric," or secondary school completion exam). Dropout increases in secondary school and peaks upon secondary completion. Re-enrollment follows a similar pattern, with re-enrollment rates highest among those with 9-11 years or more than 12 years of schooling.

The discrete choice model of this paper treats (expected) wages and school fees as the directly measurable economic factors influencing enrollment decisions; Table 3 also shows employment, wages and fees as functions of completed schooling. Employment rates, wages and school fees increase substantially upon completion of secondary school. The apparent non-linearity of returns at secondary completion motivates the inclusion of terms ( $H S G$ and $s_{p s}$, described in Table 1) allowing the intercept and slope of the expected wage equation to change in post-secondary schooling. Yet despite the large increase in fees for higher education, their (mean) reported level remains markedly lower than the corresponding wage throughout the schooling distribution.29

\subsection{Evidence consistent with dynamic updating of expected returns}

To justify the specification of a dynamic model, we must observe behavior that could not be accounted for in the static case, such as enrollment (and re-enrollment) decisions reflecting dynamic

\footnotetext{
${ }^{27}$ Moreover, it is unlikely that measurement error, in the form of recall bias, leads to a gross overstatement of re-enrollment rates. If recall bias were severe, I would expect re-enrollment rates to be greater for observations from ages before youth entered the panel and were subject to frequent interviews. Yet in a regression of the re-enrollment indicator on a dummy for whether the observation overlapped with the time of the panel, the coefficient is positive and significant (coefficient $0.03, t$-statistic 2.5), which is the opposite of the result I would expect to find in the presence of recall bias. The regression includes a full set of age and schooling dummies, controls for work experience and school failure (in both the last relevant period and cumulative), and individual fixed effects, with standard errors clustered at the individual level.

${ }^{28}$ Recall that the sample begins at age 12 , when many youth will already be close to primary school completion. Extending the sample to age 4 makes primary school enrollment nearly universal.

${ }^{29}$ These values, as with all currency-denominated units in the paper, are in real South African rand per year, base year 2002 (unless otherwise noted). The South African rand traded at 10.3 per US dollar in August 2002, when CAPS Wave 1 began.
} 
updating of expected returns following acquisition of new information. Much labor market entry and exit may occur because youth dynamically update their expectations about the relative returns to enrollment and job search based on the outcomes of their past choices. For instance, a student who fails a grade may believe she is more likely to fail in the future, as she updates her assessment of her academic ability. Similarly, a youth who succeeds in her job search may be more likely to succeed in the future, as she builds a professional network and firm-specific human capital or forms a long-term contract with her employer. Figure 3 shows that these patterns exist in the data: among those with less than 12 years of schooling, for instance, $28 \%$ of those who failed their last grade fail again, compared to just $16 \%$ of those who passed their last grade. Among those employed in their last period of non-enrollment, $62 \%$ are employed again, compared to $14 \%$ among the previously unemployed 30 If youth know these conditional probabilities of passing and employment, they may change their behavior as they update their expectations based on the outcomes of their past choices.

The transition matrices in Table 4, which show how youth in the sample move between enrollment and non-enrollment, suggest that enrollment decisions reflect such dynamic updating about returns. In the full sample, $81 \%$ of those enrolled in a given year will remain enrolled in the following year. Of those not enrolled in school, $90 \%$ will remain not enrolled in the following year, for a gross re-enrollment rate of $10 \%$. Conditioning on past outcomes reveals behavior consistent with dynamic updating of the relative returns to enrollment versus labor market participation. Among those enrollees who passed the grade level, $87 \%$ remain enrolled in the following period, while just $49 \%$ of those who failed remain enrolled. Similarly, only $4 \%$ of those employed choose to re-enroll in school in the following period, compared with $13 \%$ of the unemployed. This pattern of re-enrollment is consistent with the intuition presented in Section 2.1, in which agents who fail to find a job are more likely to re-enroll as they reassess their expected returns to labor market participation.

Transition patterns consistent with dynamic updating are present regardless of secondary completion. For both those with less than or at least 12 years of completed schooling, enrollees who failed are more likely to drop out of school than those who passed and those who were unemployed while not enrolled are more likely to re-enroll in school. This descriptive data is consistent with agents dynamically reassessing the returns to enrollment as they acquire new information based on past outcomes. The importance of such updating to the decision-making process makes a dynamic human capital investment model appropriate.

\footnotetext{
${ }^{30}$ Of course, these patterns may also simply reflect selection, as the less able and employable are more likely to fail and be unemployed, respectively, both now and in the past. The model fully specifies the dynamic selection process, however, and includes a rich set of controls to account for such selection.
} 


\section{Results}

\subsection{Parameter estimates}

Table 5 presents estimates of the model's structural parameters $\theta=\left(\phi_{e}, \phi_{j}, \alpha, \gamma\right)$. The transition parameters for school advancement and employment $\left(\phi_{e}\right.$ and $\phi_{j}$, respectively) in columns (1) and (2) are mostly as expected. In the school advancement equation of column (1), I find that conditional on all other included covariates, blacks and females are significantly more likely to pass to the next grade level. The probability of passing is increasing in ability and for those who completed at least 6 years of schooling by age 12 (again, conditional on other included variables; unconditional probabilities may differ). The probability of passing declines with the level of schooling, though the separate slope and intercept terms for high school graduates are positive, reflecting the lower failure rates in post-secondary education reported in Table 3. Grade failures, both recent and cumulative, do not significantly predict current grade failure, consistent with the aribitrariness in school performance and advancement found in Lam et al. (2011). Those living with a pension-eligible grandparent are less likely to pass, possibly reflecting a lower incentive for school performance as a result of intra-household transfers.

Column (2) shows results for the labor market transition equation (4), corresponding to the parameter $\phi_{j}$. Most coefficients have the expected sign: despite their higher rates of grade advancement, blacks and females are significantly less likely to find work than coloureds and males; the probability of employment is increasing in schooling, with a higher intercept (though no steeper gradient) for high school graduates. As hypothesized, employment is path dependent, with the coefficient on employment during the last period of non-enrollment quite large and precise. Surprisingly, those with at least 6 years of schooling at age 12 are less likely to be employed. Those enrolled in school in the previous period are more likely to be employed, suggesting that youth time their dropout decisions well ${ }^{31}$ Employment is quite sensitive to macro conditions, with a precisely estimated negative coefficient on the bad macro environment dummy.

Column (3) presents parameter estimates from the enrollment utility function of the dynamic discrete choice model, i.e., the coefficients from (3) 32 The coefficient for black shows that blacks are (conditionally) more likely to enroll in school than coloureds, consistent with the shorter school careers of coloured youth. The schooling coefficient is negative, reflecting increasing dropout rates

\footnotetext{
${ }^{31}$ The positive coefficient on enrollment in the previous period could also reflect anticipatory job search while in school, but the low rates of simultaneous enrollment and labor force participation mentioned earlier suggest otherwise.

${ }^{32} \mathrm{~A}$ note on the interpretation of coefficients from the enrollment equation in Table 5 as is well known, logit coefficients such as these are identified only up to scale. Because the units of the labor market utility function (as well as the school fee term in the enrollment utility function) are in South African rand per year (ten thousands, base year 2002), so too are the units of the enrollment utility coefficients, provided the scale parameter of the i.i.d. Type I extreme value shocks is unity, as assumed.
} 
over school careers, with a large negative coefficient upon high school graduation. The coefficients on recent and cumulative failure are negative and precisely estimated, representing strong evidence in favor of the hypothesis that youth dynamically update their enrollment behavior based on past schooling outcomes.

Since the school fee term in the enrollment utility function (3) accounts for the direct costs of schooling, the negative sign on the indicator for high school graduate may reflect any of several impediments to higher education: greater psychic costs, difficulty in obtaining admission, or credit constraints. The coefficients on all household income terms are negative, which may reflect the accumulated disadvantage of poverty, credit constraints in school financing, or both. The argument for credit constraints strengthens when considering the negative interaction terms on high school graduate and indicators for the first two household income quintiles, which means that conditional on high school graduation, youth from poorer households are less likely to enroll in post-secondary education, as also found by Lam et al. (2010). Pension recipients in the household may also provide transfers to youth to fund their studies, as suggested by the positive coefficient on co-residence with a pension-eligible grandparent. Ultimately, however, the model cannot determine whether lower post-secondary enrollment by poorer youth stems from credit constraints or accumulated disadvantage.

Coefficients for the wage equation (parameter $\gamma$ ) presented in column (4) generally show the expected pattern with respect to demographic, schooling and ability variables, with a large wage return to higher education evident in the high school graduate slope coefficient. A bad macro environment dampens wages, as expected. The school fee regressions reported in Table A2 show that fees are lower for blacks, likely reflecting lower school quality. School fees increase with grade level, with a large and discontinuous jump in post-secondary schooling.

\subsection{Model fit}

Figure 4 assesses model fit by comparing observed versus predicted grade advancement (panel [a]) and employment (panel [b]), corresponding to the transition equations (5) and (4), respectively. The model fits the data well for both types of transitions, performing poorly only in the early and post-secondary grades where the data is particularly noisy 33 Figure 5 plots enrollment probabilities for various state variables. The model does well in predicting enrollment by completed schooling (panel [a]), except in the final levels of post-secondary schooling, where small sample sizes make prediction more difficult. The model also does well in predicting enrollment as a function of previous

\footnotetext{
${ }^{33}$ Because the model begins at age 12 and relatively few students advance to post-secondary schooling, there are few observations with less than 4 or more than 12 years of schooling, as shown in the histogram (right axis) overlaying Figure 4
} 
school failure, reflecting students' learning about their academic ability: in panel (b), agents in the data and the model are less likely to enroll following a failed grade, which is also true in the case of cumulative failures, as in panel (c). Panels (b) and (c) show that the model captures how youth dynamically update their behavior based on past schooling outcomes.

Another important dimension of fit to consider is whether the model can replicate the patterns of dropout and re-enrollment observed in the data. Figure 6 presents observed and predicted dropout and re-enrollment rates by completed schooling 34 The model predicts the stylized pattern of dropout fairly well, accurately capturing the rise of dropout through the end of secondary school, although the predicted magnitudes are sometimes quite different from the data at particular levels of schooling. Similarly, the model predicts the secular rise in re-enrollment through the secondary and post-secondary school years (despite noise in the early grades due to small sample sizes).

\subsection{Robustness checks}

The model of this paper treats transitions between high school and post-secondary education and transitions between schooling and labor force participation in the same framework. Although enrollment preferences and the returns to schooling may change discontinuously at high school completion, one might worry that school to work transitions for those with post-secondary schooling are fundamentally different than for those without. To explore this possibility, I re-estimate the model using only observations from youth not enrolled in post-secondary schooling.

Table A3 shows results from the sample with no post-secondary schooling. Results are qualitatively similar to those from the full sample presented in Table 5. In particular, youth who never enroll in post-secondary schooling are more likely to drop out of school as a function of cumulative grade failures, just as in the full sample. This result suggests that the process of dynamic updating of the expected relative returns to enrollment versus labor force participation is similar for these youth. Those who failed recently tend to remain enrolled, however, suggesting that youth who have not completed secondary view grade failure as a more surmountable obstacle than those who fail in post-secondary, where failure is more rare.

One may also be concerned that my assumptions about how forward-looking youth are drives my results. In particular, one might worry that results will change dramatically depending on my choice of the discount factor $\beta$ or the time horizon $T$. Table A4, which presents estimates of the enrollment utility parameter $(\alpha)$ under alternative scenarios for $\beta$ and $T$, shows that this is not the case 35

\footnotetext{
${ }^{34}$ To calculate predicted values, I simulate 50 enrollment histories for each observation, using the state variable at age 12 (the first decision period) as the initial condition.

${ }^{35}$ Estimates of the enrollment utility parameter $\alpha$ only are shown because this is the only structural parameter that depends explicitly on the discount factor $\beta$ and the time horizon $T$ in the model. All other structural parameters remain unchanged.
} 
In columns (1) and (2), $T$ is set to ages 52 and 65 (from 60 in the main estimates), respectively; $T=52$ corresponds to South African life expectancy in 2006, while $T=65$ corresponds to the age of public pension eligibility for males prior to a recent change in the law (and therefore may have been the retirement age males had in mind when making enrollment choices). In columns (3) and (4), $\beta$ is set to 0.5 and 0.9 , respectively (from 0.95 in the main estimates). Across all columns, coefficients are generally qualitatively similar to those from the main results in column (3) of Table 5. In particular, the roles that recent and cumulative failures play in enrollment decisions do not depend on these changes to the time horizon of the model, consistent with dynamic updating ${ }^{36}$

\subsection{Alternative explanations of observed enrollment behavior}

Several alternatives to my preferred "dynamic updating" hypothesis could explain the observed enrollment patterns, among them: 1) responses to household shocks; 2) preferences for leisure; 3) credit constraints and the need to accumulate savings; and 4) behavioral explanations. I address each of these in turn.

Responses to household shocks. Youth experiencing household shocks, such as a parent's job loss or the severe illness of a household member, may choose to change their enrollment behavior abruptly as a result. Unfortunately, the available life history data are not rich enough for me to model or otherwise rule out the role of such shocks. The most detailed data on household shocks are available only during the period of the survey waves (2002-2006). In this limited panel, household shocks are not statistically associated with dropout (after controlling for grade failures, work experience, age, schooling and individual fixed effects), though contemporaneous shocks do reduce re-enrollment by 2 percentage points, as shown in Table A5, which presents linear probability models for dropout and re-enrollment in response to household shocks ${ }^{37}$ Additional data on household characteristics available throughout youth life histories include marriage, pregnancy, and co-residence with parents or grandparents, which are more properly modeled as endogenous choices rather than external shocks, and would therefore require a richer model ${ }^{38}$ However, the model in its current form is consistent with the presence of household shocks, either through their effects on

\footnotetext{
${ }^{36} \mathrm{I}$ conducted an additional robustness check in which I estimated the model without the exclusion restrictions indicated in Table 1. Again, the results (not shown, but available upon request in an unpublished appendix) are qualitatively similar to those of the preferred model of Table 5. In particular, youth respond to both recent and cumulative grade failures by enrolling less, as do youth who gain both recent and cumulative work experience, just as conjectured.

${ }^{37}$ This evidence is generally consistent with Lam et al. (2010), who find using CAPS data that household shocks (measured in Wave 3) do not significantly affect post-secondary enrollment.

${ }^{38}$ Empirically, pregnancy does not play a prominent role in dropout decisions: among new dropouts' self-reported reasons for leaving school, girls cite pregnancy $5 \%$ of the time, though the data is hampered by high rates of nonresponse.
} 
observable outcomes (such as grade advancement and employment) or through the unobservable (to the econometrician) state variable $\epsilon$.

Preferences for leisure. Some youth may prefer to take some time off from school occasionally and enjoy a period of leisure. Such a preference for leisure would be particularly likely at or near the completion of secondary school, when youth might wish to enjoy a "gap year" before continuing their studies. Yet the proportion of youth who cite economic factors (rather than other reasons more likely to signal a preference for leisure) as the reason for dropout increases to $23 \%$ among those with 12 years of schooling (compared to $12 \%$ for those with less than 12 years of schooling), precisely when we would expect youth to be taking a "gap year." 39 Moreover, a sizable fraction $(21 \%)$ of the sample drops out and re-enrolls prior to completing high school (see Table 2), before the typical "gap year" ages. This suggests that preferences for leisure, in the form of an extended period of non-enrollment, are not driving dropout and re-enrollment rates.

Credit constraints. If youth are credit constrained, they may need to drop out of school temporarily in order to accumulate savings, and re-enroll when they have saved enough to pay school fees. The relatively high rates of youth from the poorest households citing school fees as their reason for dropout (Table A6) are consistent with credit constraints. In the model I follow the existing literature (such as Cameron and Heckman 2001, Carneiro and Heckman 2002, Lam et al. 2010) and allow household income to proxy for credit constraints. Specifically, I include indicators for lower household income quintiles and their interaction with an indicator for high school graduation; the negative coefficients I find on these terms in Table 5 are consistent with the presence of credit constraints for youth from the poorest households. Yet my finding that youth dynamically update their expectations of the relative returns to enrollment versus labor market participation persists in the presence of these proxies for credit constraints.

Behavioral explanations. Many behavioral explanations are possible for the observed enrollment patterns, such as myopia or asymmetric information about the relative returns to schooling versus labor market participation. Although I do not test such alternative behavioral hypotheses directly, the model's good fit with the data suggests that these youth behave as rational, forward-thinking, and well-informed agents.

\footnotetext{
${ }^{39}$ Economic reasons for dropout include work, job search, or not being able to afford school. Non-response is the modal reason for not enrolling in school among dropouts, but the increase in those citing economic factors among high school graduates suggests that preferences for leisure do not drive dropout at that stage.
} 


\section{$5 \quad$ Policy Simulations}

In this section, I return to the motivating question of the paper: how important is the opportunity to re-enroll in the school to work transition of South African youth? To answer this question, I simulate a counterfactual scenario in which the option to re-enroll in school following dropout is restricted, and explore how enrollment decisions and outcomes change as a result. I also consider other policy simulations that potentially alter the incentives for enrollment versus labor market participation: compulsory schooling and a subsidy for post-secondary school fees. For each set of simulations, I simulate 50 enrollment histories for each observation in the data, using age 12 as the initial condition.

\section{$5.1 \quad$ Restricted re-enrollment}

Given the prevalence of re-enrollment among youth in the sample, it is natural to ask what role the option to re-enroll plays in decisions about schooling and labor market participation. Youth who know that they may re-enroll in school after a labor market spell may invest differently in human capital than those for whom labor market participation is a terminal action. The model developed in this paper is well-suited to explore the ramifications of the option to re-enroll. By fully specifying the enrollment choice environment for youth and recovering its structural parameters, the model may be adapted to consider a counterfactual scenario in which the option to re-enroll is restricted.

I modify the model by restricting re-enrollment prior to completion of high school, making labor market participation before completing grade 12 an absorbing state. I still allow for re-enrollment after high school completion, because restricting re-enrollment in the transition between secondary and post-secondary education seems particularly unrealistic. Although this scenario of restricted re-enrollment is admittedly extreme (and possibly unenforceable under the existing educational infrastructure in South Africa), it provides a useful thought experiment to assess empirically the importance of the re-enrollment option. The exercise is similar in spirit to that of Heckman and Urzua (2008), who simulate the elimination of the General Educational Development certificate (GED), a high school equivalency certificate available in the U.S. that is typically earned by high school dropouts who later re-enroll. Comparing simulated enrollment probabilities and completed schooling to analogous simulation results from the unrestricted model provides an assessment of how the option to re-enroll influences youth schooling choices and outcomes. The expected effects of such a policy are ambiguous: although restricting the freedom to enroll in school among a subpopulation (in this case, dropouts) ought to depress enrollment rates, potential dropouts facing no possibility of returning to school may choose to remain in school as a result, causing overall enrollment rates to rise. 
Figure 7 shows enrollment and dropout probabilities from the data, the unrestricted model, and the restricted re-enrollment simulation. Enrollment rates in the restricted re-enrollment scenario exceed observed and predicted (from the unrestricted model) enrollment rates through much of the schooling distribution (panel [a]), particularly among those with completed schooling of 3-13 years, where the bulk of person-year observations occur. The magnitude of these increases are striking: for example, $93 \%$ of those with 10 years of schooling enroll in school under the restricted re-enrollment scenario, compared to $55 \%$ in the data and $62 \%$ in the unrestricted model. Dropout rates are correspondingly lower in the restricted re-enrollment simulation (panel [b]). The intuition for these results is that youth facing restricted re-enrollment will be less willing to experiment in the labor market if the opportunity cost includes not only foregone human capital during a short labor market spell, but also foregone human capital in all future periods.

Table 6 shows the distribution of completed schooling at age 20 from the data and the restricted re-enrollment simulation. Column (1) reports the percentage of the sample in each schooling category under simulation of the unrestricted model; column (2) reports percentages under the restricted re-enrollment simulation; and column (3) reports the difference (standard errors in parentheses). The results show a clear rightward shift in the schooling distribution. The shares of the sample completing high school or attaining some post-secondary education climb by 1.5 and 4.7 percentage points, respectively, with corresponding declines in the lower schooling categories. The results are robust to altering how forward-looking youth are when making enrollment choices: setting the discount factor to $\beta=0.5$ (from $\beta=0.95$ ) in an otherwise identical simulation, the share completing at least 12 years of schooling by age 20 increases by 2.2 percentage points, compared to the 6.2 percentage points of the baseline simulation.

The results are qualitatively similar to those of Heckman and Urzua (2008), who use a structural schooling model to find that elimination of the GED would increase secondary completion by 2.1 percentage points in the U.S ${ }^{40}$ In both cases, restricting the option to re-enroll reduces dropout. While the magnitudes of the effects I find are larger, the large share of my sample re-enrolling in school prior to completing grade $12(21 \%)$ suggests that the restricted re-enrollment policy should indeed have a dramatic effect on the incentives faced by many youth.

A final note is in order on the welfare implications of the restricted re-enrollment simulation considered here. Restricted re-enrollment imposes costs on youth, even if it induces some to remain in school longer and complete more schooling than they otherwise would. In the unrestricted model, the possibility of re-enrollment confers option value on agents who have dropped out. Youth who choose to disenroll and re-enroll do so rationally. As forward-looking agents who compare the

\footnotetext{
${ }^{40}$ Similarly, Heckman, LaFontaine and Rodriguez (2008) find, using a panel of U.S. states, that an increase in the difficulty of passing the GED test reduced high school dropout rates.
} 
present value of enrollment and labor market participation in each period, their dropout and reenrollment decisions are rational responses to shocks such as school failure and unemployment. Any restricted re-enrollment policy reduces youth welfare by shrinking their choice set. From a social welfare perspective, restricted re-enrollment is efficient only if the resulting reduction in school dropout generates sufficiently high social returns, which I do not model in this paper. This same caveat about welfare implications applies to other policy simulations as well, in particular to the compulsory schooling simulation considered below.

\subsection{Compulsory schooling}

Schooling is compulsory in South Africa from ages 7 to 15 (or until completion of grade 9, if this occurs before age 15). Child labor laws also prohibit employment by those under age 15 . In the data, however, truancy rates in ages 12-15 reach as high as $9 \%$, with child labor rates as high as $22 \%$ among truants. Therefore, the model of this paper assumes that neither the compulsory schooling nor child labor laws are enforced. I use the model to simulate the enforcement or extension of these laws by restricting youth to be enrolled in school until a certain age; this restriction models enforcement of both the compulsory schooling and child labor laws because youth in the model may only work if they are not enrolled in school. The results of the simulation shed additional light on the option to re-enroll because compulsory schooling removes the option to drop out and re-enroll during that period.

Table 7 presents simulation results when schooling is compulsory through ages 15 and 16 (columns [2] and [3], respectively) ${ }^{41}$ Panel (a) shows the percentage of the sample in each schooling category at age 20, while panel (b) reports differences between the compulsory schooling simulation and the unrestricted model. Compulsory schooling leads to a redistribution of youth from the lower schooling categories (12 years or less) to the highest schooling category (more than 12 years). Enforcing compulsory schooling until age 15 (the existing law), for instance, leads to a decrease of 1.5 percentage points in those completing less than 9 years of schooling, and a 0.2 percentage point decrease in those with between 9-11 years. The effects are larger in magnitude when extending compulsory schooling to age 16 .

The results are qualitatively similar to those of the restricted re-enrollment simulation: in each case, the policy shifts youth up the schooling distribution by age 20 . These results are consistent with each other because each policy increases the cost of early dropout (or completely restricts it, in the case of compulsory schooling), changing the incentives for youth who might otherwise end their schooling careers. For both simulations, however, the restrictions come at the cost of reducing

\footnotetext{
${ }^{41}$ As before, I simulate 50 enrollment histories for each observation under both the unrestricted model and the compulsory schooling policy, using the state variable at age 12 as the initial condition.
} 
youth's choice sets, and therefore their individual welfare.

\subsection{Post-secondary schooling subsidy}

Given the sharp increase in school fees for post-secondary education (Table A2), I also consider how a subsidy for post-secondary education would affect enrollment. Specifically, I simulate a $25 \%$ reduction in school fees for post-secondary education by modifying the school fee term in the enrollment utility function (3) to reflect the subsidy. The post-secondary fee subsidy has small effects on the proportion of the sample enrolling in post-secondary school by age 22. Table 8 shows that in the full sample, the subsidy increases post-secondary enrollment by 0.6 percentage points. The subsidy has slightly larger effects on youth from the first two quintiles of household incomes, the groups that we would expect to respond most to the subsidy, but here the 0.7 percentage point increases are not statistically significant. The results suggest that fees do not explain much about post-secondary enrollment patterns.

The results from each policy simulation may be compared directly to the others because I use the same random draws to simulate the model under each policy. The policies have qualitatively similar effects: each policy shifts the distribution of completed schooling to the right, though the effects of the post-secondary schooling subsidy are statistically indistinguishable from zero. Restricted re-enrollment has a greater effect on the distribution of schooling than enforcement and extension of compulsory schooling, demonstrating the importance of the option to re-enroll in the schooling decisions of South African youth 42

\section{Conclusion}

In this paper, I quantify the importance of school re-enrollment in the school to work transition of South African youth. Specifically, I formulate a dynamic discrete choice model of the transition between school and work, and estimate it using a panel of young South Africans. The model accounts for uncertainty in schooling and labor market outcomes, and allows for dynamic updating of expected returns based on the outcomes of past choices. The model also allows students to re-enroll in school after a spell in the labor market, a frequent choice by South African youth but one that is largely ignored in both the literature on South Africa and in prevailing dynamic human capital models. Each of these features of the model - uncertain outcomes, dynamic updating of

\footnotetext{
${ }^{42}$ Note that all simulations ignore any general equilibrium effects that may result from the policies under consideration, following the partial equilibrium nature of the underlying model. To the extent that each policy induces youth to remain in school longer and alleviates pressure on the youth labor market, these results may represent upper bounds on the true policy effects.
} 
expectations, and the option to re-enroll - are missing from standard static human capital models, but are essential to understand the difficult transitions between school and work faced by South African youth.

Structural parameter estimates confirm the hypothesis that youth dynamically update their expectations about the relative returns to enrollment versus labor market participation based on schooling and labor market outcomes. Evidence of such dynamic updating is a key finding of this paper. The model replicates basic patterns of grade advancement, employment and enrollment observed in the data, according to characteristics such as completed schooling and recent and cumulative school failures. The estimated parameters also capture the stylized pattern of dropout and re-enrollment throughout the schooling distribution, making the model an appropriate basis for policy simulation.

I use the estimated structural parameters of the model to conduct several policy simulations that alter the incentives for enrollment versus labor market participation. In the first simulation, I restrict the option to re-enroll in school before completing grade 12, making the labor market an absorbing state for those who drop out prior to completing high school. Enrollment rates rise sharply under this restriction on re-enrollment, relative to both the data and results from the unrestricted model. The re-enrollment restriction increases the proportion of the sample completing at least 12 years of schooling by 6 percentage points. The results show that the option to re-enroll is an important component of the incentives South African youth face when making schooling decisions.

Simulations of the enforcement and extension of compulsory schooling show qualitatively similar effects as the restricted re-enrollment policy: in each case, the proportion of the sample completing 12 years of schooling or less falls, while the proportion completing more than 12 years increases. Simulation of a $25 \%$ fee subsidy for post-secondary education shows only a small effect on the proportion of the sample enrolling in post-secondary schooling, however. The results suggest that increasing the opportunity cost of school dropout (as in the restricted re-enrollment and compulsory schooling simulations) can have dramatic effects on youth enrollment decisions. Youth are less responsive to changes in the direct costs of schooling, however.

These policy simulations illustrate how enrollment behavior changes in the context of the model, and are therefore useful for quantifying the importance of various features of the school to work transition for young South Africans. It is important to remember, however, that each policy may impose important costs on public budgets (in the case of the post-secondary fee subsidy, for instance) or on youth (limiting choice through restricted re-enrollment or compulsory schooling) that are not considered in this paper. Proper policy guidance would require a more comprehensive cost-benefit analysis that builds on the results here. 
The model of this paper is quite general, and allows for straightforward extensions such as job search or employment while enrolled, or choice of educational path (e.g., academic versus vocational), that I will explore in future work. Its emphasis on uncertainty, academic and labor market shocks, and the option to re-enroll is appropriate for the South African context, where high grade repetition and unemployment make the school to work transition especially difficult. Nonetheless, the model may be relevant for other contexts as well, not only for other developing countries where youth face similarly difficult circumstances, but also developed countries in which educational choices for dropouts are an increasingly important part of human capital investment. In the United States, for instance, the prevalence of high school dropouts obtaining the GED or mid-career workers enrolling in community or for-profit colleges makes the option to re-enroll an important consideration for students.

The key findings of the model - that youth update their expected returns and enrollment decisions based on past schooling and labor market outcomes; that youth alter their enrollment behavior when the option to re-enroll after dropout is restricted; and that youth respond similarly to other changes in the costs and benefits of enrollment - suggest that a dynamic framework is essential for understanding the school to work transition in South Africa. 


\section{References}

Arcidiacono, Peter, "Ability Sorting and the Returns to College Major," Journal of Econometrics, August 2004, 121 (1), 343-75.

Banerjee, Abhijit, Sebastian Galiani, James A. Levinsohn, Zoe McLaren, and Ingrid Woolard, "A Symposium on Fostering Growth in South Africa: Why Has Unemployment Risen in the New South Africa?," Economics of Transition, 2008, 16 (4), 715-40.

Becker, Gary S., Human Capital: A Theoretical and Empirical Analysis, with Special Reference to Education, 3 ed., University Of Chicago Press, March 1994.

Belzil, Christian and Jrgen Hansen, "Unobserved Ability and the Return to Schooling," Econometrica, 2002, 70 (5), 2075-2091. ArticleType: research-article / Full publication date: Sep., 2002 / Copyright 2002 The Econometric Society.

Cameron, Stephen V. and Christopher Taber, "Estimation of Educational Borrowing Constraints Using Returns to Schooling," The Journal of Political Economy, February 2004, 112 (1), 132 182. ArticleType: research-article / Full publication date: February 2004 / Copyright 2004 The University of Chicago Press.

Cameron, Stephen V and James J Heckman, "The Dynamics of Educational Attainment for Black, Hispanic, and White Males," Journal of Political Economy, 2001, 109 (2001), 455-99.

Card, David, "The Causal Effect of Education on Earnings," Handbook of labor economics. Volume 3A. 1999, 1999, pp. 1801-63.

Carneiro, Pedro and James J. Heckman, "The Evidence on Credit Constraints in Post-Secondary Schooling," The Economic Journal, October 2002, 112 (482), 705-734. ArticleType: researcharticle / Full publication date: Oct., 2002 / Copyright 2002 Royal Economic Society.

Case, Anne, "Does Money Protect Health Status? Evidence from South African Pensions," Perspectives on the economics of aging. 2004, 2004, pp. 287-305.

and Angus Deaton, "School Inputs and Educational Outcomes in South Africa," The Quarterly Journal of Economics, 1999, 114 (3), 1047-1084. ArticleType: research-article / Full publication date: Aug., 1999 / Copyright 1999 Oxford University Press.

and Motohiro Yogo, "Does School Quality Matter? Returns to Education and the Characteristics of Schools in South Africa," National Bureau of Economic Research, 1999, (7399).

Duflo, Esther, "Grandmothers and Granddaughters: Old-Age Pensions and Intrahousehold Allocation in South Africa," World Bank Economic Review, 2003, 17 (1), 1-25.

Eckstein, Zvi and Kenneth I. Wolpin, "Why Youths Drop Out of High School: The Impact of Preferences, Opportunities, and Abilities," Econometrica, November 1999, 67 (6), 1295-1339. ArticleType: research-article / Full publication date: Nov., 1999 / Copyright 1999 The Econometric Society. 
Edmonds, Eric V, "Child Labor and Schooling Responses to Anticipated Income in South Africa," Journal of Development Economics, December 2006, 81 (2), 386-414.

Fiske, Edward B. and Helen F. Ladd, Elusive Equity: Education Reform in Post Apartheid South Africa, Brookings Institution Press, July 2004.

Heckman, J. J and S. Urzua, "The option value of educational choices and the rate of return to educational choices," in "Unpublished manuscript, University of Chicago. Presented at the Cowles Foundation Structural Conference, Yale University" 2008.

Heckman, James J. and Salvador Navarro, "Dynamic Discrete Choice and Dynamic Treatment Effects," Journal of Econometrics, February 2007, 136 (2), 341-96.

Heckman, James J, Paul A LaFontaine, and Pedro L Rodriguez, "Taking the Easy Way Out: How the GED Testing Program Induces Students to Drop Out," National Bureau of Economic Research, 2008, (14044).

Joensen, J. S., "Academic and Labor Market Success: The Impact of Student Employment, Abilities, and Preferences," Manuscript, Stockholm School of Economics, 2008.

Keane, Michael P. and Kenneth I. Wolpin, "The Career Decisions of Young Men," The Journal of Political Economy, June 1997, 105 (3), 473-522. ArticleType: research-article / Full publication date: June 1997 / Copyright 1997 The University of Chicago Press.

Keane, Michael P and Kenneth I Wolpin, "The Effect of Parental Transfers and Borrowing Constraints on Educational Attainment," International Economic Review, 2001, 2001 (4), 10511103.

Lam, D., C. Ardington, N. Branson, K. Goostrey, and M. Leibbrandt, "Credit Constraints and the Racial Gap in Post-Secondary Education in South Africa," 2010.

, Cally Ardington, Nicola Branson, Anne Case, Murray Leibbrandt, Alicia Menendez, Jeremy Seekings, and Meredith Sparks, "The Cape Area Panel Study: A Very Short Introduction to the Integrated Waves 1-2-3-4 Data," October 2008.

, M. Leibbrandt, and C. Mlatsheni, "Education and youth unemployment in South Africa," Labour markets and economic development, 2009, p. 90.

Lam, David, Cally Ardington, and Murray Leibbrandt, "Schooling as a lottery: Racial differences in school advancement in urban South Africa," Journal of Development Economics, July 2011, $95(2), 121-136$.

Levinsohn, James A. and Todd Pugatch, "Prospective Analysis of a Wage Subsidy for Cape Town Youth," National Bureau of Economic Research Working Paper Series, July 2011, No. 17248.

Light, Audrey, "Hazard Model Estimates of the Decision to Reenroll in School," Labour Economics, December 1995, 2 (4), 381-406. 
McFadden, Daniel L., "Econometric Analysis of Qualitative Response Models," in "Handbook of Econometrics," Vol. II, North-Holland, 1984, pp. 1396-1457.

Rust, John, "Optimal Replacement of GMC Bus Engines: An Empirical Model of Harold Zurcher," Econometrica, 1987, 55 (5), 999-1033. ArticleType: research-article / Full publication date: Sep., 1987 / Copyright 1987 The Econometric Society.

Souza, P., "Moral Hazard in the Family," Unpublished paper, Yale University, 2010.

Stange, Kevin, "An Empirical Examination of the Option Value of College Enrollment," Unpublished paper, University of Michigan, 2009.

Yamauchi, Futoshi, "Race, Equity, and Public Schools in Post-apartheid South Africa: Equal Opportunity for All Kids," Economics of Education Review, April 2005, 24 (2), 213-33. 


\section{A Education in South Africa}

The South African education system includes primary (grades 1-7), secondary (grades 8-12) and post-secondary (grades 13 and above) levels. Schooling is compulsory for youth aged 7-15 or through completion of grade 9 (whichever comes first), but I treat this regulation as non-binding due to the presence of non-enrolled youth in this age range in the data. To enter post-secondary schooling, students must pass a nationally standardized "matric" exam at the completion of grade 12 . Postsecondary education includes both academic and vocational programs (universities of technology, formerly Technikons). Additionally, students at the secondary level may enroll in technical colleges or vocational National Training Certificate (NTC) programs. ${ }^{43}$ For simplicity, I do not distinguish between academic and vocational education in the model. Private schools serve less than $3 \%$ of the student population in South Africa, according to government statistics; in the Western Cape province the figure is $3.1 \%$ (Fiske and Ladd 2004).

The government subsidizes public education, but students must pay fees to attend and such fees vary considerably among schools. Public schools are self-governing and are free to set their own admissions policies and fees (subject to provincial government approval). Although admissions can not discriminate based on race, test scores, or ability to pay fees, prevailing patterns of residential segregation serve to maintain quality differences among schools. Moreover, despite legal prohibitions, Fiske and Ladd (2004) conclude that "there is little doubt that many schools consider a family's likely ability to pay their fee when making admissions policy" (p. 143). Although low-income families may qualify for fee exemptions under a policy adopted in 1998, only $2.5 \%$ of primary school students and $3.7 \%$ of secondary school students receive the exemption (these figures rise to $4.1 \%$ and $5.7 \%$, respectively, in historically white schools; Fiske and Ladd 2004). At the post-secondary level, the South African government offers subsidized loans to qualified students who pass a means test through the National Student Financial Aid Scheme (NSFAS), and individual institutions also offer financing. Private banks also offer student loans at market interest rates.

\section{B Data Definitions}

The data come from retrospective life history data collected in Wave 1 of CAPS, augmented with life events recorded in Waves 2-4 ${ }^{44}$ The Wave 1 retrospective life histories record events by youth's age, where age refers to the age at which the event occurred in the case of living arrangements and marriage, and to age at the beginning of the calendar year in the case of enrollment and progression through school, labor force participation, and pregnancy. I follow this convention in mapping Wave 2-4 responses to youth's age.

\footnotetext{
${ }^{43}$ See Appendix B for information on mapping NTC programs to grade levels.

${ }^{44}$ The Cape Area Panel Study Waves 1-2-3 were collected between 2002 and 2005 by the University of Cape Town and the University of Michigan, with funding provided by the US National Institute for Child Health and Human Development and the Andrew W. Mellon Foundation. Wave 4 was collected in 2006 by the University of Cape Town, University of Michigan and Princeton University. Major funding for Wave 4 was provided by the National Institute on Aging through a grant to Princeton University, in addition to funding provided by NICHD through the University of Michigan.
} 
I make several sample restrictions. I keep only those observed until at least age 18. Those who report advancing two or more grades in a year, or without continuous information on enrollment, are dropped from the sample. I drop those who report entering school prior to age 4 or exiting school after age 24 (which effectively sets $T_{d}=24$ as the decision horizon) ${ }^{45} \mathrm{I}$ also drop those whose educational histories, by the definitions below, place them with more than 16 years of completed schooling. The restriction on observing a person until at least age 18 accounts for more than two-thirds of those dropped from the sample.

Schooling level covers grades 1-16, with National Training Certificate (NTC) I, II and III mapped to grades 10,11, and 12, respectively ${ }^{46}$ Students enrolled in university or Technikon programs that include grade 12 are considered enrolled in grade 12. Reporting successful completion of the grade level or reporting enrollment in a higher grade level in a subsequent year is considered passing the level for grades 1-12. Beginning at grade 13, reporting successful completion of the grade level or "no grade/continuing" are considered passing the level, up to a maximum of 16 years completed schooling. I make this distinction because "no grade/continuing" is the modal response for those enrolled in the post-secondary education sector, indicating that most youth are continuing in their programs of higher education, whereas "passing" reports at these levels drop considerably. Unfortunately, I am unable to determine whether students are making satisfactory progress towards degree completion. All other results while enrolled are considered failure. I define "dropout" as disenrollment following a year of enrollment, and "re-enrollment" as enrollment following a year of non-enrollment. Schooling histories in which levels regress with age are re-coded so that such regression can not occur. Grades failed represent the accumulation of periods of enrollment in which the agent did not pass the grade, and therefore may include events such as withdrawal, illness or residential moves rather than outright academic failure. I top-code grades failed and work experience since age 12 at 3 and 4, respectively, which reduces the dimension of the state space while still accurately capturing more than $99 \%$ of the person-year observations in the sample.

Labor force participation variables (i.e., work and search) and wages are conditional on nonenrollment at a given age, where reports of enrollment supersede reports of labor market participation. School fees are conditional on enrollment, and include total household expenditure on fees and other educational expenses in real rand per year (base year 2002). Wages are full-time annual equivalent based on 160 working hours per month (those reporting monthly hours above 160 are considered full-time and do not receive an adjustment). Wages and school fees are available only at the time of the interview, rather than as retrospective histories; predicted values are imputed based on observed characteristics for purposes of estimation. For both expected wages and school fees, I replace predicted values below the minimum value observed in the sample with the first percentile from the data, in order to avoid non-positive predicted values and extreme outliers. Work experience includes only those periods of simultaneous work and non-enrollment; I exclude work experience while enrolled in school 47

\footnotetext{
${ }^{45}$ Reporting school entry prior to age 4 is more likely to reflect measurement error than childhood precociousness, in my view. Few observations are available in the data after age 24 (less than $20 \%$ of the sample is observed beyond 24, due to starting ages in Wave 1 and attrition), raising concern that estimating the model with these enrollment choices will result in severe finite-sample bias.

${ }^{46} \mathrm{NTC}$ conversion based on coding in CAPS, derived variable w1h_higrd.

${ }^{47}$ Work or search while enrolled peaks at $3.2 \%$ across all grade levels, and never exceeds $2 \%$ during grades $1-12$.
} 
Other covariates are largely self-explanatory. Ability quartiles refers to in-sample rank of ageadjusted score on the literacy and numeracy evaluation (LNE) administered to all CAPS respondents in Wave 1. Unfortunately, because this ability measure was taken in Wave 1, when the sampled youth were at least age 14, it is not predetermined with respect to enrollment choices in the model, which begins at age 12. I include it, however, because it is a measure common to all in the sample, and therefore helps to distinguish between the role of ability and human capital investment in labor market returns. To mitigate bias in the LNE score due to age differences in Wave 1, I adjust for age as follows: using the estimation sample, I regress the standardized literacy and numeracy evaluation (LNE) score on age and age squared at Wave 1 (when the test was administered) and get predicted residuals. I then sort observations into quartiles based on these residuals. Household income quintiles are derived from the distribution of household per capita income reported in Wave 1 of CAPS 48 The pension-eligible grandparent indicator is set to one if the young adult reports living with a grandparent at the given age and there is at least one grandparent on the household roster who is of pension-eligible age (60 for females, 65 for males). The variable definition also makes note of changes in the household roster reported in Waves 2-4.

I calibrate the wage-age profile for years following the decision horizon (i.e., from periods $T_{d}+1$ to $T$ ) using the $10 \%$ public use micro-sample of the 2001 South African Census. First, I define the estimation sample as native-born residents of urban areas in Western Cape province (which includes metropolitan Cape Town, from which CAPS respondents are drawn) who are ages 25-64, in the labor force, and classify themselves as one of the three major racial groups (white, black, or coloured). I also exclude the self-employed and unpaid workers, leaving a sample of $n=111,772$. I then predict employment and income by running logit and OLS regressions, respectively, using as controls race and gender dummies, years of schooling, a high school graduate dummy, race-schooling and racehigh school graduate interactions, age and age squared ${ }^{49}$ I then create an expected income variable for each observation as the product of these predicted values (i.e., $\mathbb{E}(\widehat{\text { income }})=\widehat{\operatorname{Pr}(\text { work })} \times \widehat{\text { income }})$, and regress expected income on the same set of controls. I save the coefficients on age and age squared from this regression for use in the wage equation of the structural model; the coefficients on age and age squared are 3,695.3 and -45.9 , respectively 50 The macro environment variable is based on the South African employment/population ratio for 15-24 year olds, from the World Bank Africa Development Indicators.

All variables measured in monetary values used in this paper are in real South African rand per year (base year 2002), unless otherwise noted. The South African rand traded at 10.3 per US dollar in August, 2002 when CAPS Wave 1 began.

\footnotetext{
${ }^{48}$ Due to non-response, $7 \%$ of the sample uses imputed values for household income, based on multiple imputation conducted by CAPS.

${ }^{49}$ The included controls are the largest subset (other than age variables) of the controls used in the structural model that are available in the Census. Note that interactions of schooling and the high school graduate dummy are not included because the maximum years of schooling reported in the Census is 13. I use income rather than wages because the latter are unavailable in the Census. I adjust income to 2002 South African rand to be consistent with the base year of CAPS.

${ }^{50}$ Since I care only about the coefficients, inconsistent estimation of their standard errors due to the generated outcome variable is not problematic in this context.
} 
Table 1: Elements of observable state space $X$ and exclusion restrictions

\begin{tabular}{|c|c|c|c|c|}
\hline$\overline{\text { Variable }}$ & $\overline{\text { Description }}$ & enrollment & passing & $\begin{array}{c}\text { wage/ } \\
\text { employment }\end{array}$ \\
\hline \multicolumn{5}{|c|}{ Time-invariant $\left(X_{0}\right)$ : } \\
\hline race & $\mathbb{I}($ race $=$ black $)$ & $\mathrm{x}$ & $\mathrm{x}$ & $\mathrm{x}$ \\
\hline$g$ & $\mathbb{I}($ female $)$ & $\mathrm{x}$ & $\mathrm{x}$ & $\mathrm{x}$ \\
\hline$s_{0}$ & $\mathbb{I}($ schooling $\geq 6$ at $t=0)$ & $\mathrm{x}$ & $\mathrm{x}$ & $\mathrm{x}$ \\
\hline$z_{q}$ & $\mathbb{I}($ ability quartile $=q)$ & $\mathrm{x}$ & $\mathrm{x}$ & $\mathrm{x}$ \\
\hline$y_{q}$ & $\begin{array}{l}\mathbb{I}(\text { household income quintile }=q) \\
\quad \text { for } q=1,2\end{array}$ & $\mathrm{x}$ & & \\
\hline \multicolumn{5}{|c|}{ Time-varying $\left(X_{t}\right)$ : } \\
\hline$s$ & schooling & $\mathrm{x}$ & $\mathrm{x}$ & $\mathrm{x}$ \\
\hline$f_{t o t}$ & total grades failed since $t=0$ & $\mathrm{x}$ & $\mathrm{x}$ & \\
\hline$f$ & $\mathbb{I}$ (failed last grade enrolled) & $\mathrm{x}$ & $\mathrm{x}$ & \\
\hline$x_{t o t}$ & work experience & & & $\mathrm{x}$ \\
\hline$x$ & $\mathbb{I}$ (worked last period not enrolled) & & & $\mathrm{x}$ \\
\hline$H S G$ & $\mathbb{I}$ (high school graduate) & $\mathrm{x}$ & $\mathrm{x}$ & $\mathrm{x}$ \\
\hline$s_{p s}$ & post-secondary schooling & $\mathrm{x}$ & $\mathrm{x}$ & $\mathrm{x}$ \\
\hline$y_{q} * H S G$ & interactions between $y_{q}$ and $H S G$ & $\mathrm{x}$ & & \\
\hline$g p$ & pension-eligible grandparent & $\mathrm{x}$ & $\mathrm{x}$ & $\mathrm{x}$ \\
\hline$d_{-1}$ & $\mathbb{I}($ enrolled last period $)$ & $\mathrm{x}$ & $\mathrm{x}$ & $\mathrm{x}$ \\
\hline$\zeta$ & $\mathbb{I}(\text { bad macro environment })^{\dagger}$ & & & $\mathrm{x}$ \\
\hline
\end{tabular}

${ }^{\dagger}$ A bad macro environment is a year in which the employment/population ratio for $15-24$ year olds is less than $25 \%$. Between 1991-2006, this occurred in 2002-2003.

Note: "x" denotes inclusion in equation, by column. Enrollment refers to equation (3); passing refers to (5); wage/employment refers to 2 and 4 . 
Table 2: Summary statistics

\begin{tabular}{lrrr}
\hline \hline Variable & Obs. & Mean & Std. Dev. \\
\hline female & 3374 & 0.54 & 0.50 \\
black & 3374 & 0.34 & 0.47 \\
coloured & 3374 & 0.66 & 0.47 \\
age of school entry & 3374 & 6.3 & 1.1 \\
age last enrolled & 3374 & 17.6 & 2.3 \\
completed schooling & 3374 & 10.5 & 2.1 \\
grades failed & 3374 & 1.4 & 1.3 \\
schooling at age 12 & 3374 & 5.3 & 1.3 \\
LNE score & 3374 & 0.00 & 0.90 \\
ever re-enrolled & 3374 & 0.31 & 0.46 \\
ever re-enrolled, grade 1-12 & 3374 & 0.21 & 0.41 \\
passed matric (high school) & 3374 & 0.42 & 0.49 \\
ever enrolled in post-secondary & 3374 & 0.18 & 0.38 \\
ever worked & 3374 & 0.53 & 0.50 \\
work experience & 3374 & 1.1 & 1.3 \\
wage (FTE, max.) & 2340 & 32,960 & 28,222 \\
\hline \hline
\end{tabular}

LNE score is from literacy and numeracy evaluation administered in CAPS Wave 1, normalized to mean zero and standard deviation one. Wage is annual full-time equivalent based on 160 monthly hours, maximum over all individual's observations in panel, in South African rand (real, base year 2002). Survey weights applied.

Table 3: Choices and outcomes by completed schooling

\begin{tabular}{lcccc}
\hline \hline & \multicolumn{4}{c}{ Completed Schooling } \\
\cline { 3 - 5 } & $<9$ & $9-11$ & 12 & $>12$ \\
\hline enrollment & 0.77 & 0.55 & 0.17 & 0.45 \\
failure & 0.11 & 0.28 & 0.13 & 0.03 \\
dropout & 0.06 & 0.23 & 0.68 & 0.35 \\
re-enrollment & 0.04 & 0.14 & 0.10 & 0.21 \\
employed & 0.18 & 0.26 & 0.40 & 0.44 \\
wages & 19,914 & 24,471 & 29,833 & 43,269 \\
school fee & 398 & 1,188 & 7,089 & 10,307 \\
\hline \hline
\end{tabular}

Cells report survey-weighted fraction of relevant person-year observations in each category, based on completed schooling at beginning of year. Enrollment proportions are unconditional. Failure conditions on enrollment. Dropout conditions on enrollment in previous year. Re-enrollment conditions on non-enrollment in previous year. Employment conditions on nonenrollment. Wages conditions on employment. School fee conditions on enrollment. Wage is annual full-time equivalent based on 160 monthly hours, maximum over all individual's observations in panel, in South African rand (real, base year 2002). School fee in South African rand (real, base year 2002). 
Table 4: Transition matrices between enrollment and non-enrollment

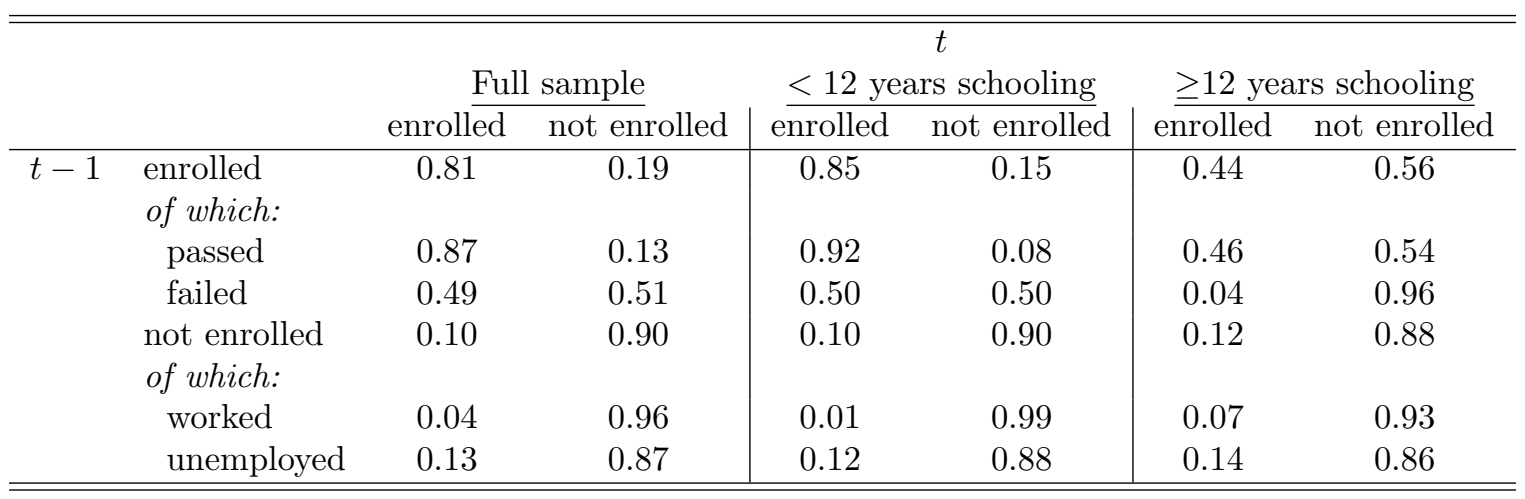

Cells show transitions from state at time $t-1$ to state at time $t$. Survey-weighted means reported. 
Table 5: Structural parameter estimates

\begin{tabular}{|c|c|c|c|c|}
\hline $\begin{array}{l}\text { equation } \\
\text { parameters }\end{array}$ & $\begin{array}{c}(1) \\
\text { pass } \\
\phi_{e}\end{array}$ & $\begin{array}{c}(2) \\
\text { work } \\
\phi_{j}\end{array}$ & $\begin{array}{c}(3) \\
\text { enrollment } \\
\alpha\end{array}$ & $\begin{array}{c}(4) \\
\text { wage } \\
\gamma\end{array}$ \\
\hline black & $\begin{array}{c}0.21 \\
(0.08)\end{array}$ & $\begin{array}{l}-0.98 \\
(0.07)\end{array}$ & $\begin{array}{c}3.12 \\
(0.20)\end{array}$ & $\begin{array}{l}-0.65 \\
(0.06)\end{array}$ \\
\hline female & $\begin{array}{c}0.26 \\
(0.05)\end{array}$ & $\begin{array}{l}-0.42 \\
(0.06)\end{array}$ & $\begin{array}{c}0.31 \\
(0.13)\end{array}$ & $\begin{array}{l}-0.59 \\
(0.06)\end{array}$ \\
\hline $\mathbb{I}($ schooling $\geq 6$, age 12$)$ & $\begin{array}{c}0.57 \\
(0.06)\end{array}$ & $\begin{array}{l}-0.15 \\
(0.06)\end{array}$ & $\begin{array}{c}0.74 \\
(0.14)\end{array}$ & $\begin{array}{c}0.23 \\
(0.07)\end{array}$ \\
\hline ability quartile 2 & $\begin{array}{c}0.46 \\
(0.06)\end{array}$ & $\begin{array}{l}-0.24 \\
(0.08)\end{array}$ & $\begin{array}{c}0.08 \\
(0.16)\end{array}$ & $\begin{array}{l}-0.02 \\
(0.07)\end{array}$ \\
\hline ability quartile 3 & $\begin{array}{c}0.72 \\
(0.07)\end{array}$ & $\begin{array}{c}0.04 \\
(0.09)\end{array}$ & $\begin{array}{l}-0.17 \\
(0.17)\end{array}$ & $\begin{array}{c}0.07 \\
(0.08)\end{array}$ \\
\hline ability quartile 4 & $\begin{array}{c}1.57 \\
(0.09)\end{array}$ & $\begin{array}{c}0.17 \\
(0.09)\end{array}$ & $\begin{array}{l}-0.65 \\
(0.22)\end{array}$ & $\begin{array}{c}0.66 \\
(0.11)\end{array}$ \\
\hline HH income quintile 1 & & & $\begin{array}{l}-0.77 \\
(0.10)\end{array}$ & \\
\hline HH income quintile 2 & & & $\begin{array}{l}-0.66 \\
(0.10)\end{array}$ & \\
\hline schooling & $\begin{array}{l}-0.35 \\
(0.02)\end{array}$ & $\begin{array}{c}0.27 \\
(0.03)\end{array}$ & $\begin{array}{l}-0.17 \\
(0.08)\end{array}$ & $\begin{array}{c}0.14 \\
(0.02)\end{array}$ \\
\hline high school graduate & $\begin{array}{l}1.58 \\
(0.16)\end{array}$ & $\begin{array}{c}0.45 \\
(0.09)\end{array}$ & $\begin{array}{r}-10.36 \\
(0.95)\end{array}$ & $\begin{array}{c}0.03 \\
(0.10)\end{array}$ \\
\hline post-secondary schooling & $\begin{array}{c}1.13 \\
(0.26)\end{array}$ & $\begin{array}{c}0.03 \\
(0.04)\end{array}$ & $\begin{array}{l}-0.02 \\
(0.57)\end{array}$ & $\begin{array}{c}1.08 \\
(0.15)\end{array}$ \\
\hline $\begin{array}{l}\text { failed last grade } \\
\text { enrolled }\end{array}$ & $\begin{array}{l}-0.11 \\
(0.13)\end{array}$ & & $\begin{array}{l}-2.92 \\
(0.67)\end{array}$ & \\
\hline $\begin{array}{l}\text { cumulative grades failed } \\
\text { since age } 12\end{array}$ & $\begin{array}{l}-0.01 \\
(0.11)\end{array}$ & & $\begin{array}{l}-1.21 \\
(0.19)\end{array}$ & \\
\hline $\begin{array}{l}\text { worked last period } \\
\text { not enrolled }\end{array}$ & & $\begin{array}{c}2.40 \\
(0.11)\end{array}$ & & $\begin{array}{l}-0.06 \\
(0.08)\end{array}$ \\
\hline work experience & & $\begin{array}{c}0.01 \\
(0.05)\end{array}$ & & $\begin{array}{c}0.13 \\
(0.03)\end{array}$ \\
\hline $\mathrm{HH}$ income quintile $1^{*} H S G$ & & & $\begin{array}{l}-0.53 \\
(0.16)\end{array}$ & \\
\hline HH income quintile $2^{*} H S G$ & & & $\begin{array}{l}-0.57 \\
(0.22)\end{array}$ & \\
\hline pension-eligible grandparent & $\begin{array}{c}-0.24 \\
(0.09)\end{array}$ & $\begin{array}{l}-0.10 \\
(0.10)\end{array}$ & $\begin{array}{c}0.48 \\
(0.22)\end{array}$ & $\begin{array}{c}0.05 \\
(0.09)\end{array}$ \\
\hline enrolled last period & $\begin{array}{c}-0.23 \\
(0.13)\end{array}$ & $\begin{array}{c}0.23 \\
(0.12)\end{array}$ & $\begin{array}{c}6.63 \\
(0.29)\end{array}$ & $\begin{array}{c}(0.29) \\
(0.10)\end{array}$ \\
\hline $\mathbb{I}$ (bad macro environment) & & $\begin{array}{l}-1.01 \\
(0.11)\end{array}$ & & $\begin{array}{l}-0.87 \\
(0.07)\end{array}$ \\
\hline constant & $\begin{array}{c}3.63 \\
(0.26)\end{array}$ & $\begin{array}{l}-3.82 \\
(0.28)\end{array}$ & $\begin{array}{l}-1.89 \\
(0.63)\end{array}$ & $\begin{array}{c}1.32 \\
(0.17)\end{array}$ \\
\hline $\begin{array}{l} \\
\ln L \\
R^{2}\end{array}$ & \multicolumn{3}{|c|}{$-2,296,703.0$} & $\begin{array}{l}4,088 \\
0.23\end{array}$ \\
\hline
\end{tabular}

Sample is black and coloured youth from CAPS life history panel, ages 12-26. Parameter estimates obtained by first sequentially estimating columns (1), (2) and (4); plugging initial estimates into partial likelihood function to obtain preliminary estimates of column (3); then conducting one Newton iteration over full information likelihood function to obtain final estimates. Estimates in column (4) are initial estimates because these one Newton iteration over full information likelihood function to obtain final estimates. Estimates in column (4) are initial estimates because these
parameters are not otherwise identified using full information likelihoo 3 Gunction. All estimates use survey weights. All standard errors robust. Wages are full-time equivalent, based on 160 hours of work per month, in tens of thousands of real rand per year (constant 2002 values). Model units for enrollment equation same as wage equation. Cumulative failure since age 12 top-coded at 3 . Work experience top-coded at 4 . "Bad macro environment" refers to employment/population ratio for 15-24 year olds below 25 percent. 
Table 6: Distribution of completed schooling at age 20 under restricted re-enrollment (before high school completion) simulation

\begin{tabular}{c|ccc}
\hline \hline & unrestricted & $\begin{array}{c}\text { restricted } \\
\text { re-enrollment }\end{array}$ & difference \\
Completed schooling & $(1)$ & $(2)$ & $(2)-(1)$ \\
\hline$<9$ years & 8.1 & 4.1 & -4.0 \\
& $(0.1)$ & $(0.1)$ & $(0.1)$ \\
$9-11$ years & 39.8 & 37.6 & -2.1 \\
& $(0.2)$ & $(0.1)$ & $(0.2)$ \\
12 years & 17.4 & 18.9 & 1.5 \\
& $(0.1)$ & $(0.1)$ & $(0.2)$ \\
& 34.7 & 39.4 & 4.7 \\
& $(0.2)$ & $(0.2)$ & $(0.2)$ \\
\hline \hline
\end{tabular}

Table shows distribution of completed schooling at age 20 in unrestricted model and under "no re-enrollment before high school completion" simulation. Percentage of sample within each completed schooling category shown (standard error in parenthesis). In simulation, 50 simulated histories are generated for each observation. Column (1) shows simulation results of unrestricted model. Column (2) shows simulation results in which re-enrollment restricted prior to high school completion. Column (3) shows difference is means, Column (1) minus Column (2). All results calculated using survey weights. 
Table 7: Distribution of completed schooling at age 20 under compulsory schooling simulation

\begin{tabular}{cccc}
\hline \hline $\begin{array}{c}\text { Final compulsory } \\
\text { schooling age }\end{array}$ & unrestricted & age 15 & age 16 \\
& $(1)$ & $(2)$ & $(3)$ \\
\hline Panel (a): percent of sample in schooling category & \\
$<9$ years & 8.1 & 6.6 & 5.9 \\
& $(0.1)$ & $(0.1)$ & $(0.1)$ \\
$9-11$ years & 39.8 & 39.6 & 39.5 \\
& $(0.2)$ & $(0.2)$ & $(0.2)$ \\
12 years & 17.4 & 17.2 & 17.1 \\
& $(0.1)$ & $(0.1)$ & $(0.1)$ \\
$>12$ years & 34.7 & 36.7 & 37.5 \\
& $(0.2)$ & $(0.2)$ & $(0.2)$ \\
\hline Panel (b): Difference (compulsory schooling minus unrestricted model) \\
$<9$ years & & -1.5 & -2.2 \\
& & $(0.1)$ & $(0.1)$ \\
9 - 11 years & -0.2 & -0.3 \\
& & $(0.2)$ & $(0.2)$ \\
12 years & -0.2 & -0.3 \\
& & $(0.2)$ & $(0.2)$ \\
& & 1.9 & 2.8 \\
& & $(0.2)$ & $(0.2)$ \\
\hline \hline
\end{tabular}

Table shows distribution of completed schooling at age 20 in unrestricted model and under compulsory schooling simulation. Percentage of sample within each completed schooling category (Panel [a]) or difference between compulsory schooling simulation and unrestricted model (Panel [b]) shown (standard error in parenthesis). In simulation, 50 simulated histories are generated for each observation. Column (1) shows simulation results of unrestricted model. Columns (2)-(3) shows simulation results in which schooling made compulsory through ages 15 and 16, respectively. All results calculated using survey weights. 
Table 8: Proportion enrolling in post-secondary schooling by age 22 under post-secondary fee subsidy

\begin{tabular}{lccc}
\hline \hline & $\begin{array}{c}\text { Predicted } \\
\text { (no subsidy) }\end{array}$ & $\begin{array}{c}\text { Predicted } \\
\text { (25\% subsidy) }\end{array}$ & Difference \\
& $(1)$ & $(2)$ & $(2)-(1)$ \\
\hline full sample & 63.6 & 64.2 & 0.6 \\
& $(0.2)$ & $(0.2)$ & $(0.3)$ \\
household income quintile & & & \\
first (bottom) & 49.2 & 49.8 & 0.7 \\
& $(0.4)$ & $(0.4)$ & $(0.5)$ \\
second & 54.5 & 55.2 & 0.7 \\
& $(0.4)$ & $(0.4)$ & $(0.6)$ \\
\hline \hline
\end{tabular}

Table shows percentage of sample enrolling in post-secondary education by age 22, by indicated characteristic, based on model simulation. In simulation, 50 simulated histories are generated for each observation. Column (1) shows simulation results of unrestricted model. Column (2) shows simulation results in which post-secondary fees reduced by 25\%. Column (3) shows difference is means, Column (2) minus Column (1). All results calculated using survey weights. All results calculated using survey weights. 
Table A1: Panel balance

\begin{tabular}{lrcccc}
\hline \hline & & \multicolumn{3}{c}{ Proportion censored at age } \\
\cline { 3 - 6 } & $N$ & 18 & 20 & 22 & 24 \\
\hline full sample & 3,374 & 0.00 & 0.26 & 0.57 & 0.82 \\
black & 1,714 & 0.00 & 0.26 & 0.55 & 0.81 \\
coloured & 1,660 & 0.00 & 0.27 & 0.57 & 0.82 \\
\hline \hline
\end{tabular}

Cells show number of observations $(N)$ or percent of sample with missing enrollment information by age. Survey weights used in calculation.

Table A2: Predicted school fees

\begin{tabular}{lc}
\hline \hline black & -0.08 \\
& $(0.02)$ \\
schooling & 0.05 \\
& $(0.01)$ \\
high school graduate & 0.67 \\
& $(0.05)$ \\
constant & -0.28 \\
& $(0.08)$ \\
\hline$N$ & 2,644 \\
$R^{2}$ & 0.28 \\
\hline \hline
\end{tabular}

Table shows coefficients in school fee prediction equation. Unit of observation is person-year, where school fees measured in South African rand per year (ten thousands). In enrollment utility (3), school fee set to first percentile of school fee distribution if predicted school fee falls below minimum observed school fee in sample. Survey weights used in regression. 
Table A3: Structural parameter estimates (no post-secondary schooling)

\begin{tabular}{|c|c|c|c|c|}
\hline $\begin{array}{l}\text { equation } \\
\text { parameters }\end{array}$ & $\begin{array}{c}(1) \\
\text { pass } \\
\phi_{e}\end{array}$ & $\begin{array}{c}(2) \\
\text { work } \\
\phi_{j}\end{array}$ & $\begin{array}{c}(3) \\
\text { enrollment } \\
\alpha\end{array}$ & $\begin{array}{c}(4) \\
\text { wage } \\
\gamma\end{array}$ \\
\hline black & $\begin{array}{c}0.31 \\
(0.06)\end{array}$ & $\begin{array}{l}-0.89 \\
(0.07)\end{array}$ & $\begin{array}{c}3.10 \\
(0.24)\end{array}$ & $\begin{array}{l}-0.61 \\
(0.06)\end{array}$ \\
\hline female & $\begin{array}{c}0.27 \\
(0.05)\end{array}$ & $\begin{array}{l}-0.35 \\
(0.06)\end{array}$ & $\begin{array}{c}0.15 \\
(0.22)\end{array}$ & $\begin{array}{l}-0.64 \\
(0.06)\end{array}$ \\
\hline $\mathbb{I}($ schooling $\geq 6$, age 12$)$ & $\begin{array}{c}0.58 \\
(0.06)\end{array}$ & $\begin{array}{l}-0.14 \\
(0.07)\end{array}$ & $\begin{array}{c}1.92 \\
(0.23)\end{array}$ & $\begin{array}{c}0.22 \\
(0.07)\end{array}$ \\
\hline ability quartile 2 & $\begin{array}{c}0.43 \\
(0.06)\end{array}$ & $\begin{array}{l}-0.12 \\
(0.08)\end{array}$ & $\begin{array}{c}0.41 \\
(0.27)\end{array}$ & $\begin{array}{c}0.00 \\
(0.06)\end{array}$ \\
\hline ability quartile 3 & $\begin{array}{c}0.77 \\
(0.06)\end{array}$ & $\begin{array}{c}0.01 \\
(0.09)\end{array}$ & $\begin{array}{c}0.70 \\
(0.25)\end{array}$ & $\begin{array}{c}0.06 \\
(0.08)\end{array}$ \\
\hline ability quartile 4 & $\begin{array}{l}1.60 \\
(0.08)\end{array}$ & $\begin{array}{l}-0.12 \\
(0.10)\end{array}$ & $\begin{array}{l}1.47 \\
(0.32)\end{array}$ & $\begin{array}{c}0.64 \\
(0.12)\end{array}$ \\
\hline $\mathrm{HH}$ income quintile 1 & & & $\begin{array}{l}-0.55 \\
(0.25)\end{array}$ & \\
\hline HH income quintile 2 & & & $\begin{array}{l}-0.73 \\
(0.32)\end{array}$ & \\
\hline schooling & $\begin{array}{l}-0.38 \\
(0.02)\end{array}$ & $\begin{array}{c}0.18 \\
(0.05)\end{array}$ & $\begin{array}{c}0.21 \\
(0.15)\end{array}$ & $\begin{array}{c}0.15 \\
(0.02)\end{array}$ \\
\hline high school graduate & & $\begin{array}{c}0.72 \\
(0.09)\end{array}$ & & $\begin{array}{c}0.06 \\
(0.10)\end{array}$ \\
\hline $\begin{array}{l}\text { failed last grade } \\
\text { enrolled } \\
\text { cumulative grades failed } \\
\text { since age } 12\end{array}$ & $\begin{array}{l}0.20 \\
(0.11) \\
-0.56 \\
(0.06)\end{array}$ & & $\begin{array}{l}0.78 \\
(0.40) \\
-4.11 \\
(0.16)\end{array}$ & \\
\hline $\begin{array}{l}\text { worked last period } \\
\text { not enrolled }\end{array}$ & & $\begin{array}{c}3.54 \\
(0.17)\end{array}$ & & $\begin{array}{l}-0.13 \\
(0.08)\end{array}$ \\
\hline work experience & & $\begin{array}{l}-0.37 \\
(0.08)\end{array}$ & & $\begin{array}{c}0.14 \\
(0.03)\end{array}$ \\
\hline pension-eligible grandparent & $\begin{array}{c}-0.10 \\
(0.08)\end{array}$ & $\begin{array}{l}-0.06 \\
(0.09)\end{array}$ & $\begin{array}{c}0.33 \\
(0.23)\end{array}$ & $\begin{array}{c}0.00 \\
(0.09)\end{array}$ \\
\hline enrolled last period & $\begin{array}{c}0.11 \\
(0.27)\end{array}$ & $\begin{array}{c}1.03 \\
(0.10)\end{array}$ & $\begin{array}{l}12.41 \\
(0.37)\end{array}$ & $\begin{array}{l}-0.33 \\
(0.09)\end{array}$ \\
\hline $\mathbb{I}$ (bad macro environment) & & $\begin{array}{l}-1.77 \\
(0.08)\end{array}$ & & $\begin{array}{l}-0.81 \\
(0.06)\end{array}$ \\
\hline constant & $\begin{array}{c}3.61 \\
(0.40)\end{array}$ & $\begin{array}{l}-2.60 \\
(0.40)\end{array}$ & $\begin{array}{l}-4.13 \\
(1.37)\end{array}$ & $\begin{array}{c}1.26 \\
(0.17)\end{array}$ \\
\hline $\begin{array}{l}N \\
\ln L \\
R^{2}\end{array}$ & \multicolumn{3}{|c|}{$\begin{array}{c}3,314 \\
-1,740,102.5\end{array}$} & 3,763 \\
\hline
\end{tabular}

Sample is black and coloured youth from CAPS life history panel, ages 12-26, excluding observations with post-secondary schooling. Parameter estimates obtained by first sequentially estimating columns (1), (2) and (4); plugging initial estimates into partial likelihood function to obtain preliminary estimates of column (3); then conducting one Newton iteration over full information likelihood function to obtain final estimates. Estimates in column (4) are initial estimates because these parameters are not otherwise identified using full information likelihood function. All estimates use survey weights. All standard errors robust. Wages are full-time equivalent, based on 160 hours of work per month, in tens of thousands of real rand per year (constant 2002 values). Model units for enrollment equation same as wage equation. Cumulative failure since age 12 top-coded at 3. Work experience top-coded at 4. "Bad macro environment" refers to employment/population ratio for 15-24 year olds below 25 percent. 
Table A4: Enrollment parameter estimates (robustness checks)

\begin{tabular}{|c|c|c|c|c|}
\hline & $\begin{array}{c}1(1) \\
T=52\end{array}$ & $\begin{array}{c}(2) \\
T=65\end{array}$ & $\begin{array}{c}(3) \\
\beta=.5\end{array}$ & $\begin{array}{c}(4) \\
\beta=.9\end{array}$ \\
\hline black & $\begin{array}{c}2.97 \\
(0.38)\end{array}$ & $\begin{array}{c}2.99 \\
(0.17)\end{array}$ & $\begin{array}{c}0.37 \\
(0.06)\end{array}$ & $\begin{array}{c}2.00 \\
(0.14)\end{array}$ \\
\hline female & $\begin{array}{c}0.27 \\
(0.14)\end{array}$ & $\begin{array}{c}0.31 \\
(0.15)\end{array}$ & $\begin{array}{l}-0.25 \\
(0.05)\end{array}$ & $\begin{array}{c}0.00 \\
(0.10)\end{array}$ \\
\hline $\mathbb{I}($ schooling $\geq 6$, age 12$)$ & $\begin{array}{c}0.54 \\
(0.13)\end{array}$ & $\begin{array}{c}0.84 \\
(0.15)\end{array}$ & $\begin{array}{c}0.35 \\
(0.06)\end{array}$ & $\begin{array}{c}0.25 \\
(0.11)\end{array}$ \\
\hline ability quartile 2 & $\begin{array}{c}0.16 \\
(0.18)\end{array}$ & $\begin{array}{c}0.14 \\
(0.19)\end{array}$ & $\begin{array}{c}0.24 \\
(0.07)\end{array}$ & $\begin{array}{c}0.25 \\
(0.13)\end{array}$ \\
\hline ability quartile 3 & $\begin{array}{l}-0.11 \\
(0.17)\end{array}$ & $\begin{array}{l}-0.19 \\
(0.19)\end{array}$ & $\begin{array}{c}0.30 \\
(0.08)\end{array}$ & $\begin{array}{c}0.14 \\
(0.13)\end{array}$ \\
\hline ability quartile 4 & $\begin{array}{l}-0.52 \\
(0.21)\end{array}$ & $\begin{array}{l}-0.61 \\
(0.24)\end{array}$ & $\begin{array}{c}1.14 \\
(0.08)\end{array}$ & $\begin{array}{c}0.29 \\
(0.16)\end{array}$ \\
\hline HH income quintile 1 & $\begin{array}{l}-0.68 \\
(0.10)\end{array}$ & $\begin{array}{l}-0.81 \\
(0.13)\end{array}$ & $\begin{array}{l}-0.44 \\
(0.07)\end{array}$ & $\begin{array}{l}-0.38 \\
(0.09)\end{array}$ \\
\hline HH income quintile 2 & $\begin{array}{l}-0.58 \\
(0.10)\end{array}$ & $\begin{array}{l}-0.72 \\
(0.13)\end{array}$ & $\begin{array}{l}-0.36 \\
(0.07)\end{array}$ & $\begin{array}{l}-0.36 \\
(0.09)\end{array}$ \\
\hline schooling & $\begin{array}{l}-0.04 \\
(0.17)\end{array}$ & $\begin{array}{c}0.01 \\
(0.07)\end{array}$ & $\begin{array}{l}-0.02 \\
(0.02)\end{array}$ & $\begin{array}{l}-0.06 \\
(0.04)\end{array}$ \\
\hline high school graduate & $\begin{array}{l}-9.38 \\
(1.33)\end{array}$ & $\begin{array}{l}-10.65 \\
(1.10)\end{array}$ & $\begin{array}{l}-2.59 \\
(0.27)\end{array}$ & $\begin{array}{l}-4.90 \\
(0.41)\end{array}$ \\
\hline post-secondary schooling & $\begin{array}{c}0.00 \\
(0.66)\end{array}$ & $\begin{array}{l}-1.16 \\
(0.88)\end{array}$ & $\begin{array}{c}1.17 \\
(0.11)\end{array}$ & $\begin{array}{c}1.39 \\
(0.59)\end{array}$ \\
\hline $\begin{array}{l}\text { failed last grade } \\
\text { enrolled }\end{array}$ & $\begin{array}{l}-2.58 \\
(0.65)\end{array}$ & $\begin{array}{l}-2.51 \\
(0.65)\end{array}$ & $\begin{array}{l}-2.11 \\
(0.10)\end{array}$ & $\begin{array}{l}-1.89 \\
(0.27)\end{array}$ \\
\hline $\begin{array}{l}\text { cumulative grades failed } \\
\text { since age } 12\end{array}$ & $\begin{array}{l}-1.09 \\
(0.44)\end{array}$ & $\begin{array}{l}-1.72 \\
(0.17)\end{array}$ & $\begin{array}{l}-0.74 \\
(0.04)\end{array}$ & $\begin{array}{l}-0.88 \\
(0.08)\end{array}$ \\
\hline $\mathrm{HH}$ income quintile $1^{*} H S G$ & $\begin{array}{l}-0.64 \\
(0.16)\end{array}$ & $\begin{array}{l}-0.41 \\
(0.16)\end{array}$ & $\begin{array}{c}1.22 \\
(0.28)\end{array}$ & $\begin{array}{l}-0.50 \\
(0.19)\end{array}$ \\
\hline $\mathrm{HH}$ income quintile $2^{*} H S G$ & $\begin{array}{l}-0.68 \\
(0.20)\end{array}$ & $\begin{array}{l}-0.47 \\
(0.31)\end{array}$ & $\begin{array}{c}1.07 \\
(0.29)\end{array}$ & $\begin{array}{l}-0.50 \\
(0.22)\end{array}$ \\
\hline pension-eligible grandparent & $\begin{array}{c}0.32 \\
(0.21)\end{array}$ & $\begin{array}{c}0.42 \\
(0.21)\end{array}$ & $\begin{array}{l}-0.03 \\
(0.08)\end{array}$ & $\begin{array}{c}0.05 \\
(0.17)\end{array}$ \\
\hline enrolled last period & $\begin{array}{c}5.81 \\
(0.39)\end{array}$ & $\begin{array}{c}7.37 \\
(0.40)\end{array}$ & $\begin{array}{c}3.46 \\
(0.07)\end{array}$ & $\begin{array}{c}4.68 \\
(0.18)\end{array}$ \\
\hline constant & $\begin{array}{l}-2.59 \\
(1.30)\end{array}$ & $\begin{array}{l}-3.05 \\
(0.64)\end{array}$ & $\begin{array}{c}0.39 \\
(0.17)\end{array}$ & $\begin{array}{l}-0.94 \\
(0.32)\end{array}$ \\
\hline $\begin{array}{l}N \\
\ln L\end{array}$ & $\begin{array}{c}3,374 \\
-2,260,252.2\end{array}$ & $\begin{array}{c}3,374 \\
-2,309,604.1\end{array}$ & $\begin{array}{c}3,374 \\
-2,135,589.8\end{array}$ & $\begin{array}{c}3,374 \\
-2,188,398.2\end{array}$ \\
\hline
\end{tabular}

Table shows enrollment utility parameter $(\alpha)$ estimates under modifications to model, as indicated by column. All estimates use survey weights. All standard errors robust, obtained by conducting one Newton iteration over full information likelihood function, using estimates from sequential maximimum likelihood as starting values. Model units scaled to 10,000 South African rand per year (constant 2002 values). 
Table A5: Dropout and re-enrollment in response to household shocks

\begin{tabular}{lcccc}
\hline \hline & $(1)$ & $(2)$ & $(3)$ & $(4)$ \\
& dropout & $\begin{array}{c}(4) \\
\text { dropout }\end{array}$ & $\begin{array}{c}\text { re-enroll } \\
\text { re-enroll }\end{array}$ \\
\hline household shock & -0.001 & & -0.020 & \\
& $(0.031)$ & & $(0.010)^{* *}$ & \\
household shock $(a-1)$ & & -0.038 & & 0.001 \\
& & $(0.093)$ & & $(0.017)$ \\
failed last grade enrolled & 0.270 & 0.135 & & \\
& $(0.053)^{* * *}$ & $(0.122)$ & & \\
cumulated grades failed & 0.169 & 0.323 & & -0.009 \\
& $(0.051)^{* * *}$ & $(0.134)^{* *}$ & & -0.027 \\
worked last period of non-enrollment & & & $(0.017)$ & $(0.021)$ \\
& & & -0.002 & -0.036 \\
work experience & & & $(0.013)$ & $(0.049)$ \\
\hline Observations & 4085 & 2576 & 4568 & 3081 \\
R-squared & 0.79 & 0.83 & 0.79 & 0.9 \\
\hline \hline
\end{tabular}

Sample is person-years for which household shock defined. All regressions include individual, age and schooling fixed effects. "Household shock" refers to death; serious illness or injury; job loss; business failure or bankruptcy; abandonment or divorce; theft, fire or property damage; or other major shock. Contemporaneous and lagged household shock coefficients not included in same regression because they are not separately identified, due to lack of observations with both variables for the same individual in the sample. Standard errors clustered by individual.

Table A6: Can't afford school (among dropouts)

\begin{tabular}{lccc}
\hline \hline Full sample & 0.08 & 0.08 & 0.07 \\
Household income quintile & & & \\
$\quad$ first & 0.14 & 0.12 & 0.22 \\
second & 0.09 & 0.09 & 0.13 \\
third & 0.06 & 0.05 & 0.07 \\
fourth & 0.03 & 0.04 & 0.03 \\
fifth & 0.01 & 0.02 & 0.01 \\
\hline \hline
\end{tabular}

Cells report survey-weighted fraction of observations in person-year panel reporting "can't afford school" as reason for nonenrollment in period immediately after dropout. Sample is "new" dropouts, i.e., those who have dropped out of school after enrolling in the previous year. 
Figure 1: K-10 enrollment at age 20 in South Africa and selected countries

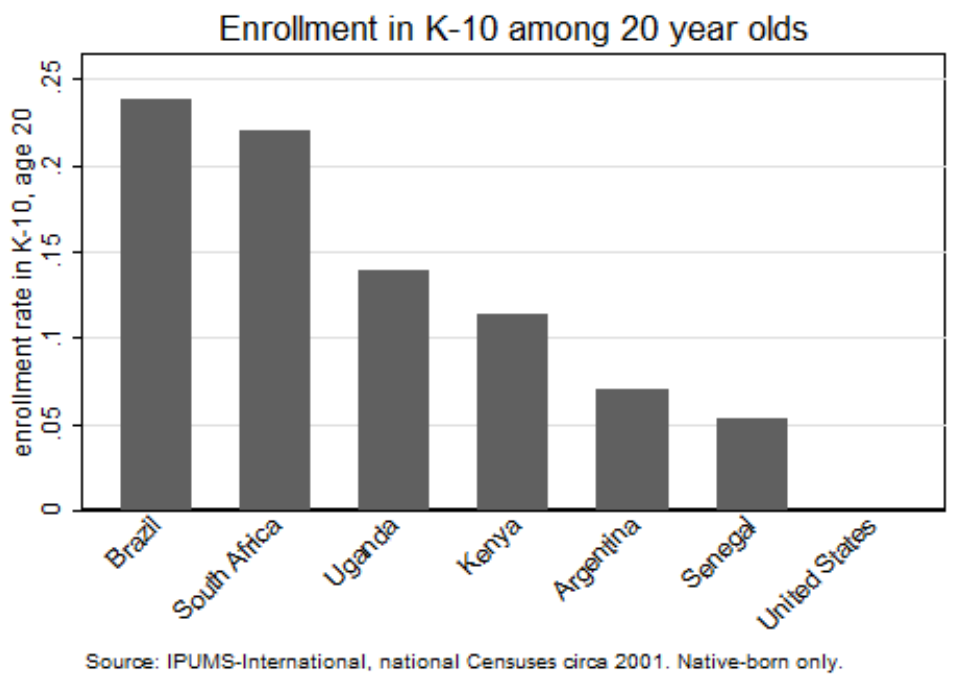




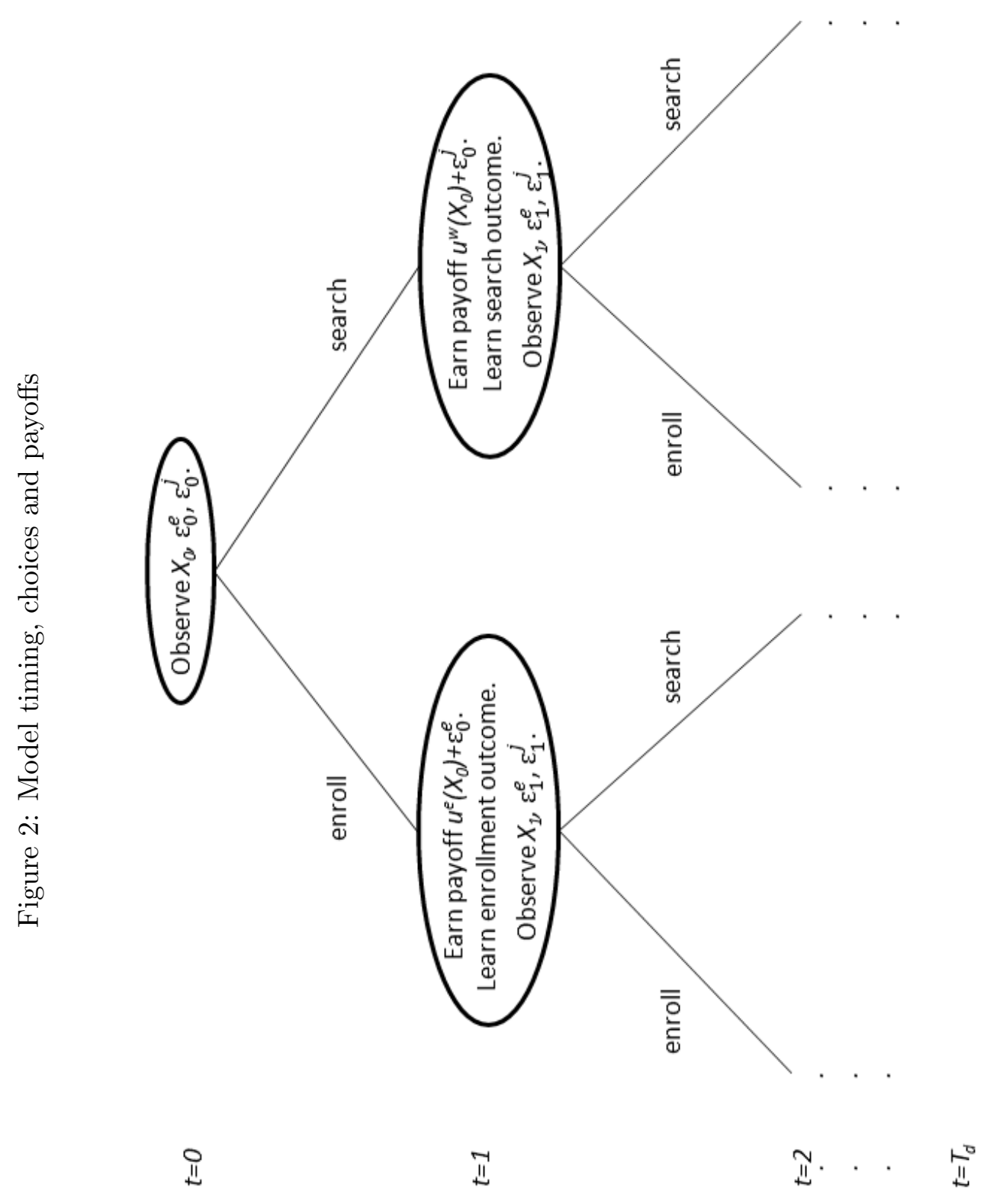


Figure 3: Failure and employment rates, by last outcome

(a)

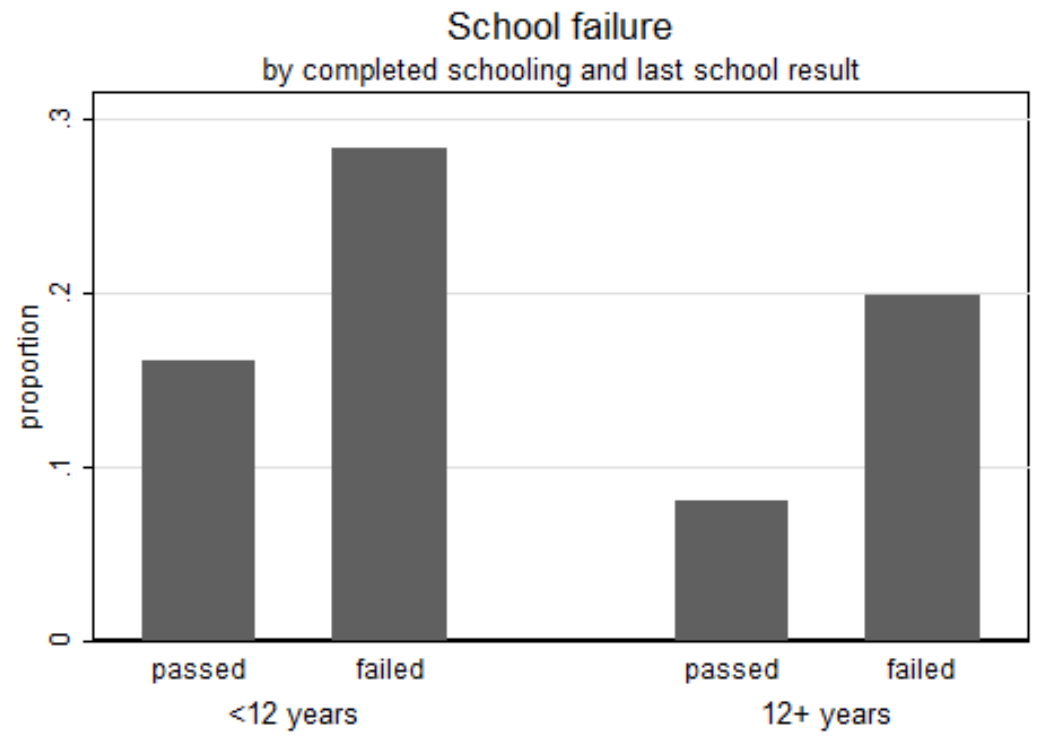

(b)

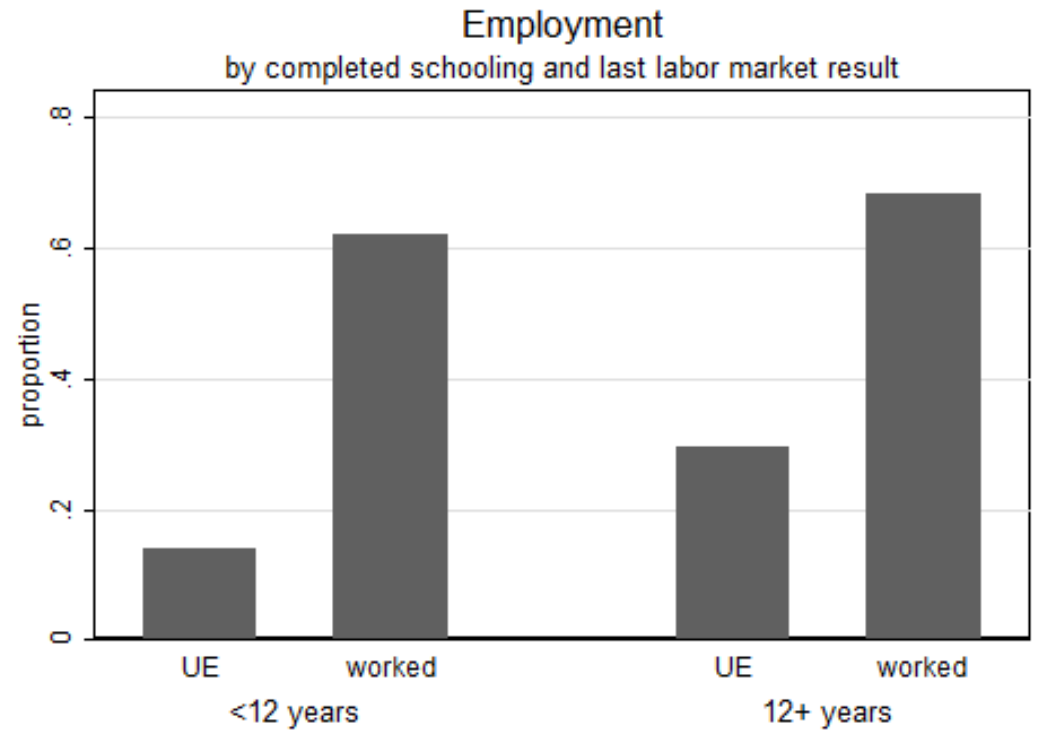

Panel (a) shows proportion of enrollees (person-year observations) who fail current grade, conditional on schooling outcome of last enrollment period and completed schooling category. Panel (b) shows employment rates among non-enrollees (person-year observations), conditional on labor market outcome of last non-enrollment period and completed schooling category. 
Figure 4: Model fit: grade advancement and employment

(a)

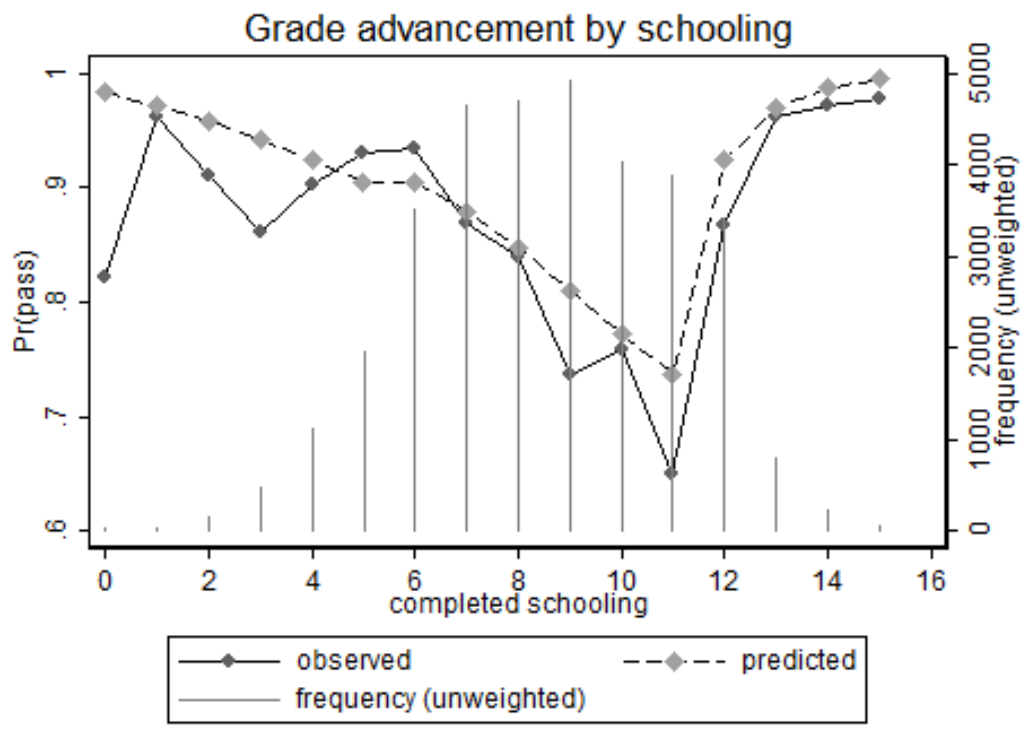

(b)

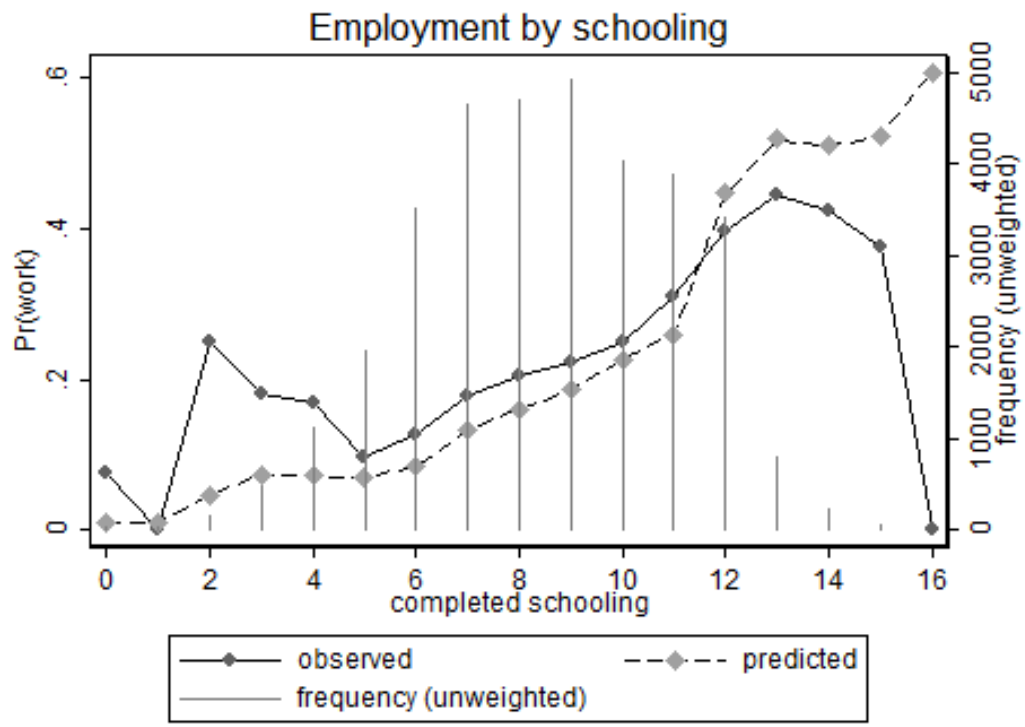

Figure shows labeled characteristics among person-year observations in sample, conditional on completed schooling, i.e., proportion advancing to next grade among person-year observations with $s$ years completed schooling. Grade advancement rates condition on current school enrollment. Employment rates condition on current non-enrollment. Predicted grade advancement and employment calculated as $\int \operatorname{Pr}(y \mid S, \hat{\theta}) f(S) d S$ for $y=$ pass, work, using observed distribution of states $S$ and survey weights. Histogram of person-year observations by completed schooling also depicted (right vertical axis). 
Figure 5: Model fit: enrollment

(a)

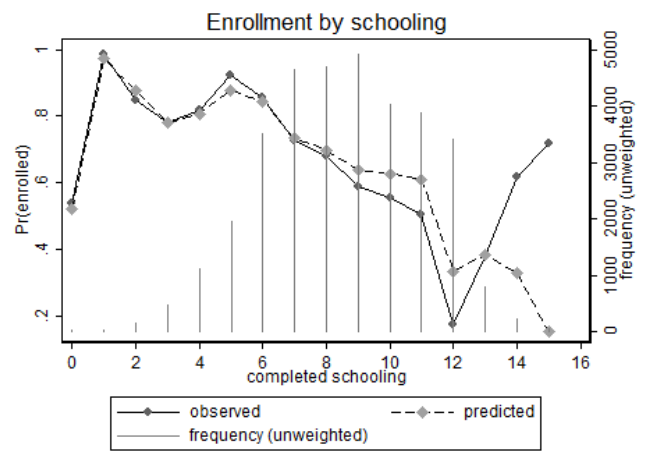

(b)

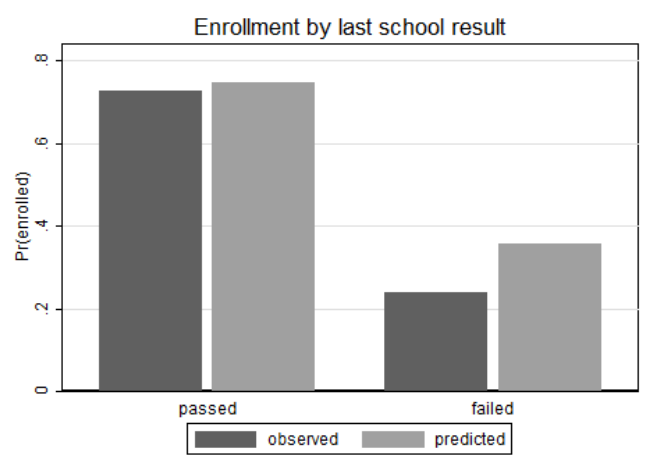

(c)

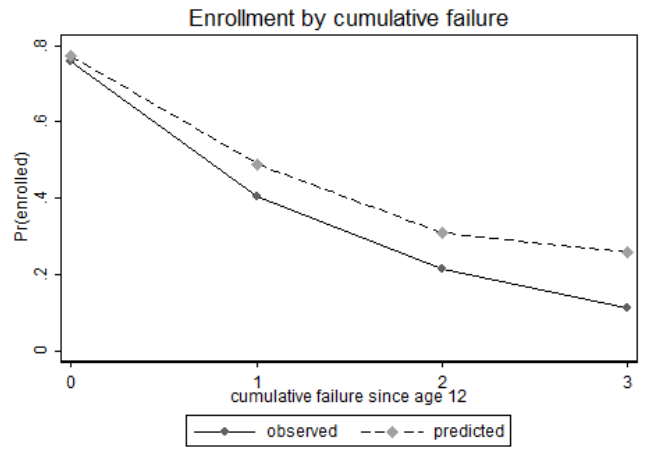

Figure shows enrollment rates among person-year observations in sample, conditional on labeled characteristics, i.e., proportion enrolled in school among person-year observations with $s$ years completed schooling. Predicted enrollment calculated as $\int \operatorname{Pr}(d \mid S, \hat{\theta}) f(S) d S$, using observed distribution of states $S$ and survey weights. Histogram of person-year observations by completed schooling also depicted in panel (a), right vertical axis. 
Figure 6: Model fit: dropout and re-enrollment

(a)

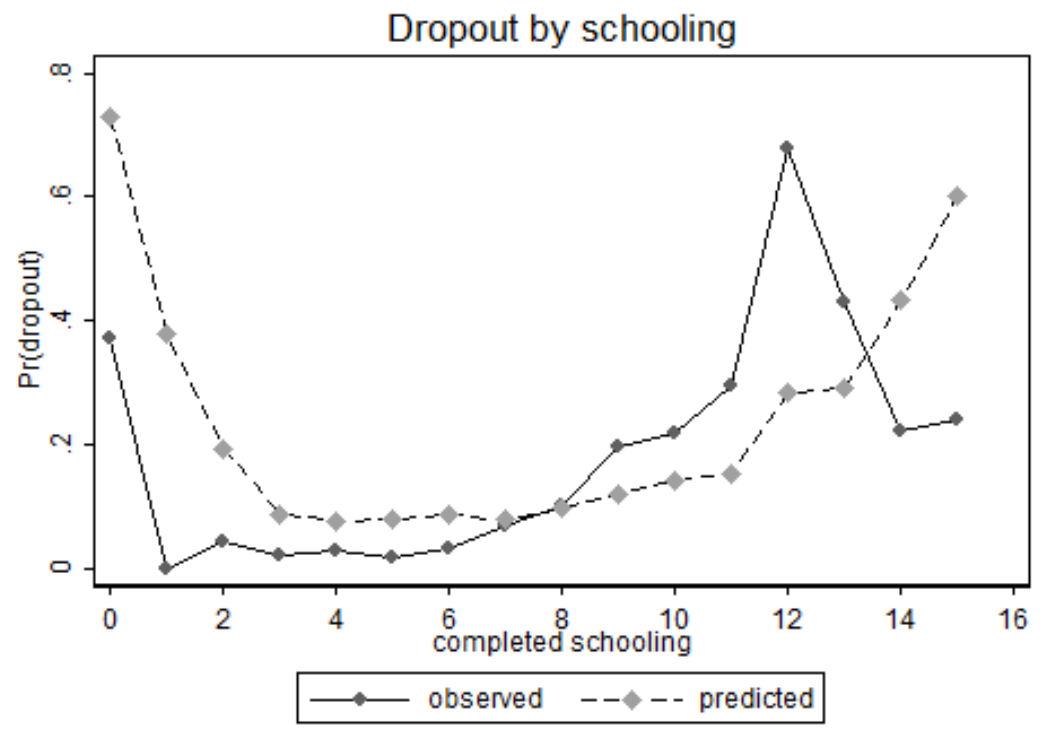

(b)

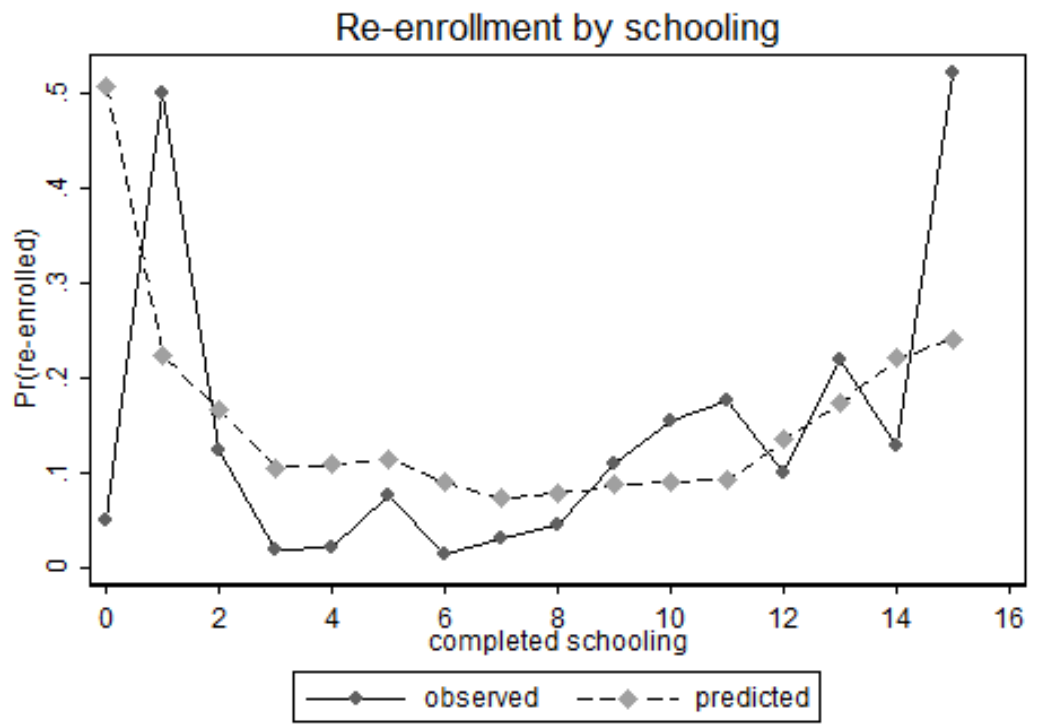

Figure shows dropout and re-enrollment among eligible person-year observations in sample, conditional on completed schooling. Dropout refers to disenrollment after a period of enrollment, i.e., $\operatorname{Pr}($ not enrolled at $t$ enrolled at $t-1$, schooling $=s)$. Reenrollment refers to enrollment after at least one period of disenrollment, so that figure depicts $\operatorname{Pr}($ enroll at $t \mid$ not enrolled at $t-$ 1 , schooling $=s$ ). Predicted values calculated as $\int \operatorname{Pr}(y \mid S, \hat{\theta}) f(S) d S$ from simulation in which enrollment history simulated 50 times for each observation in the dataset, using the observed state at $t=1$ (age 12) as the initial condition. Predicted dropout and re-enrollment are undefined for age 12 because no simulated prior history exists at that age. 
Figure 7: Restricted re-enrollment simulation

(a)

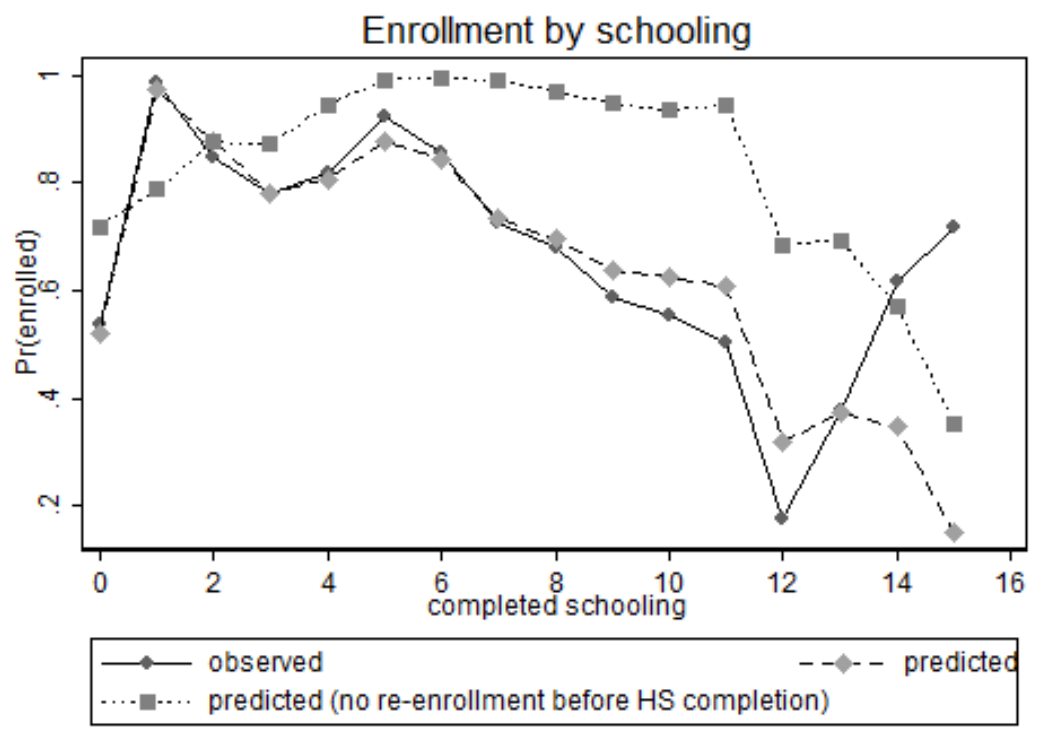

(b)

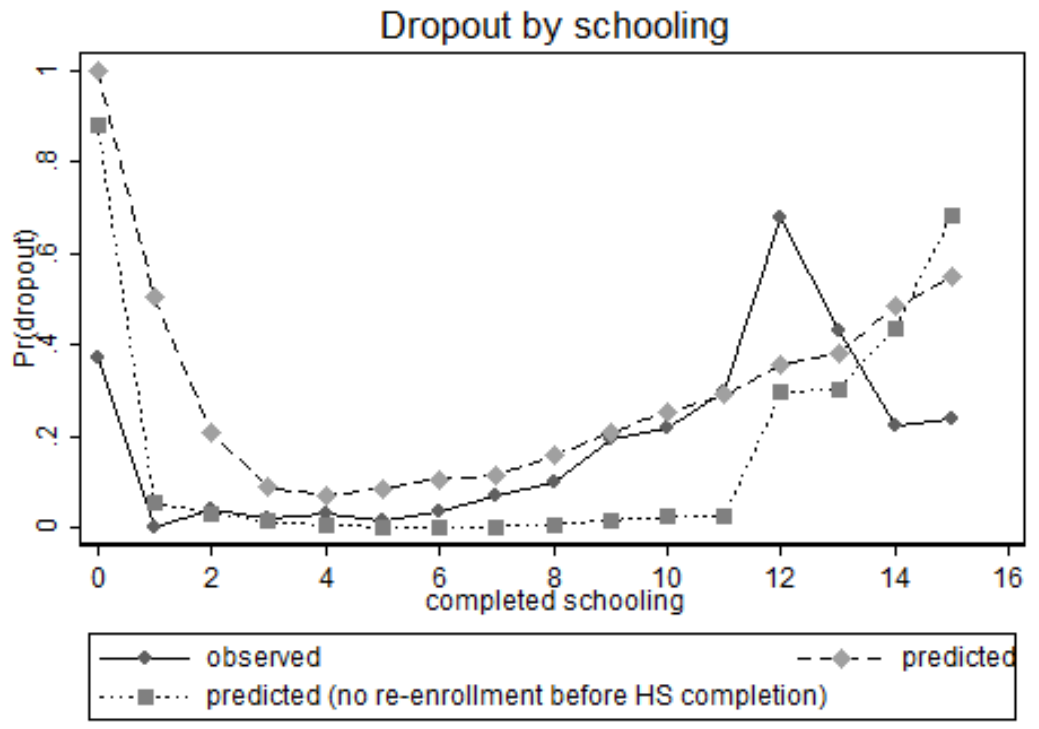

Figure shows enrollment and dropout among person-year observations in sample, conditional on completed schooling. Dropout refers to disenrollment after a period of enrollment, i.e., $\operatorname{Pr}$ (not enrolled at $t$ enrolled at $t-1$, schooling $=s$ ). Predicted values calculated as $\int \operatorname{Pr}(y \mid S, \hat{\theta}) f(S) d S$ from simulation in which enrollment history simulated 50 times for each observation in the dataset under "no re-enrollment before high school completion" restriction, using the observed state at $t=1$ (age 12) as the initial condition. Predicted dropout is undefined for age 12 because no simulated prior history exists at that age. 